OPEN ACCESS

Edited by:

Kevin G. Bath,

Brown University, United States

Reviewed by:

Susanne Brummelte, Wayne State University,

United States

Deborah Hodgson,

University of Newcastle, Australia

${ }^{*}$ Correspondence: Irina P. Butkevich irinabutkevich@yandex.ru

Received: 04 February 2019 Accepted: 22 May 2019

Published: 11 June 2019

Citation:

Butkevich IP, Mikhailenko VA, Vershinina EA and Barr GA (2019) Differences Between the Prenatal Effects of Fluoxetine or Buspirone Alone or in Combination on Pain and Affective Behaviors in Prenatally Stressed Male and Female Rats.

Front. Behav. Neurosci. 13:125 doi: 10.3389/fnbeh.2019.00125

\section{Differences Between the Prenatal Effects of Fluoxetine or Buspirone Alone or in Combination on Pain and Affective Behaviors in Prenatally Stressed Male and Female Rats}

\author{
Irina P. Butkevich ${ }^{1,2 *}$, Viktor A. Mikhailenko ${ }^{1}$, Elena A. Vershinina ${ }^{3}$ and Gordon A. Barr ${ }^{4}$ \\ ${ }^{1}$ Laboratory of Ontogenesis of the Nervous System, I.P. Pavlov Institute of Physiology, Russian Academy of Sciences, \\ St. Petersburg, Russia, ${ }^{2}$ Department of Normal Physiology, State Pediatric Medical University, St. Petersburg, Russia, \\ ${ }^{3}$ Department of Information Technologies and Mathematical Modeling, I.P. Pavlov Institute of Physiology, Russian Academy of \\ Sciences, St. Petersburg, Russia, ${ }^{4}$ Department of Anesthesiology and Critical Care Medicine, The Children's Hospital of \\ Philadelphia and the Perelman School of Medicine at the University of Pennsylvania, Philadelphia, PA, United States
}

The selective serotonin reuptake inhibitor fluoxetine and the 5-HT1A receptor agonist buspirone are used to treat depression and anxiety. Previously we demonstrated that chronic stress during pregnancy (prenatal stress) in rats, used as a model of maternal depression risk, increased inflammatory pain and depressive-like behavior in the offspring; buspirone injected to pregnant dams was protective. Clinically, the addition of buspirone to fluoxetine increases the latter's efficacy in treating depression in patients. Here, we investigated the influence of repeated prenatal injections of fluoxetine, buspirone or their combination on pain- and depressive-like behaviors in prenatally stressed young male and female rats. Prenatal stress augmented depressive-like behavior and both thermal and inflammatory pain (formalin test), replicating our prior findings, and increased basal levels of corticosterone in the blood plasma. Both drugs and their combination reduced the effects of prenatal stress on thermal pain and depressive-like behavior independently of sex. The combination of fluoxetine and buspirone, compared with fluoxetine, was more antinociceptive in the hot plate test in both sexes, and when compared with buspirone, was more antinociceptive only in males. A detailed study of the time-course of formalininduced pain showed a nuanced effect of these drugs that was sex-dependent. The combination of the two drugs was less effective in females than males during the initial acute phase of nociceptive behavior in flexing + shaking behaviors, whereas that combination was more effective than fluoxetine alone in the first acute phase of licking behavior in females. The antinociceptive effect of buspirone dominated that of the drug combination and of fluoxetine alone, especially during the interphase of the formalin test in both sexes for both flexing + shaking and licking, suggesting a more effective prenatal action of buspirone on the development of a descending 
serotonergic inhibitory system modulating pain in the spinal cord dorsal horn neurons. Our results indicate that inflammatory pain-like responses integrated at the spinal level in males were more vulnerable to prenatal stress than females. In licking, the antinociceptive effect of fluoxetine and drug combination in the interphase was more in males than females. The data underscore the importance of considering sexual dimorphism when using drug therapy.

\section{Keywords: fluoxetine, buspirone, combination of the drugs, prenatal stress, pain, depression, adolescent rat, sex} differences

\section{INTRODUCTION}

Clinical and experimental studies have found that strong and/or persistent stress during pregnancy (prenatal stress) is associated with lasting dysfunction in the central nervous system (CNS) that increases vulnerability towards affective disorders (Weinstock, 2010; Entringer et al., 2015; Kundakovic and Jaric, 2017; Scheinost et al., 2017; Hartman and Belsky, 2018; Huizink and de Rooij, 2018). In addition to increased risk of affective disorders, prenatal stress alters other neurobehavioral functions, including pain perception. Our knowledge of prenatal stress effects on reactivity of the pain, however, is limited (Sternberg and Ridgway, 2003; Sun et al., 2013; Knaepen et al., 2014). In animal studies, maternal stress replicates risk factors for depression as well as other psychosocial disorders (Weinstock, 2008, 2017). Prenatal stress can influence the offspring's neurodevelopment via multiple ways. Prenatal stress alters serotonergic function (Van den Hove et al., 2006; Gemmel et al., 2018; Kiryanova et al., 2018; Soares-Cunha et al., 2018), the hypothalamopituitary-adrenal axis (Gemmel et al., 2017; Morsi et al., 2018), GABA-ergic (Nejatbakhsh et al., 2018), and glutamatergic systems (Cattane et al., 2018; Lin et al., 2018) and immune system function (Bittle and Stevens, 2018; Goldstein et al., 2019).

The serotonin 1A receptor subtype (5-HT1AR) and glucocorticoid receptors (GR) are thought to be the main targets of prenatal stress (Van den Hove et al., 2006; Kiryanova et al., 2018). The serotonergic system and the HPA axis are closely interrelated (Andrews and Matthews, 2004; Wyrwoll and Holmes, 2012). GR are on neurons in the CNS regions classically associated with nociception and there is evidence that HPA axis directly influences nociception, particularly pre- and perinatally (Shagura et al., 2016; Zouikr et al., 2016). In the last week of the rat fetal development, the levels of corticosteroids in the blood increase, peaking 1 day before term (Waddell and Atkinson, 1994). The expression of 5-HT1AR first appears in the rat during the initial stages of embryonic development of the hippocampus (Patel and Zhou, 2005). 5-HT1AR is highly expressed in the limbic system, prefrontal cortex (PFC), raphe nuclei, and spinal cord (Popova and Naumenko, 2013). The former two CNS structures are of particular relevance in affective behavior and the etiology of depressive disorders (Liu et al., 2017), and the latter two, in pain processing and its modulation (Wang and Nakai, 1994). Neuroanatomical and functional connections among these structures determine the integration of nociceptive and affective signals and the involvement of the descending serotonergic system that regulates nociceptive signals in pain and depressive behaviors (Chaouloff, 2000). Since 5-HT1AR is involved in nociception (Granados-Soto et al., 2010) and psycho-emotional behavior (Savitz et al., 2009), changes in its activity in the prenatal period may manifest itself later in alteration of various types of adaptive behaviors (Knaepen et al., 2013, 2014; Kiryanova et al., 2017, 2018; Pawluski and Gemmel, 2018).

There is increasing evidence to suggest that the 5 -HT1AR is involved in depression and the actions of antidepressant drugs (Savitz et al., 2009; Carr and Lucki, 2011; Richardson-Jones et al., 2011) and is an important target for the pharmacological treatment of disorders in the CNS (Lacivita et al., 2008; Berrocoso and Mico, 2009; Albert and Fiori, 2014; Turcotte-Cardin et al., 2019). Of the selective serotonin reuptake inhibitors (SSRIs) used for the treatment of depression, fluoxetine is among those recommended for pregnant women (Kaihola et al., 2016). SSRIs cross the placental barrier (Pohland et al., 1989; Ewing et al., 2015), bind to the serotonin transporter (SERT) and block the presynaptic reuptake of serotonin $(5-\mathrm{HT})$, thus increasing the level of 5-HT in the synaptic gap (Kiryanova et al., 2013). Since 5 -HT is a key regulator of early developmental processes in the CNS (Lauder, 1990), disruption of 5-HT balance in the fetus can affect its development and lead to altered adaptive behavior in later life. However, fluoxetine does not reduce the level of depression in all patients, so attempts have been made to improve its efficacy. A number of clinical observations in adult patients suffering from depression suggest that the combination of 5-HTIA receptor agonists with SSRI's improves therapeutic outcomes (Pierz and Thase, 2014; Wang et al., 2015). For instance, the antidepressant vilazodone (Stuivenga et al., 2019) integrates properties of a partial 5-HT1A receptor agonist with SERT blockade. Despite a number of positive results with the use of SSRIs in combination with agonists of 5-HT1A receptors in adult patients, there continues to be a need for a systematic study of results of the influence of such types of combination in animal models (Stuivenga et al., 2019). It should be noted that our knowledge of the possible antinociceptive effect of SSRIs (Dharmshaktu et al., 2012; Zammataro et al., 2017; Barakat et al., 2018; Hamdy et al., 2018), as well as buspirone (Giordano and Rogers, 1992; Pavlaković et al., 2009; Haleem et al., 2018) is limited, and the available data are inconsistent.

Buspirone is widely used for treating generalized anxiety disorder (Albert and François, 2010; Albert and Fiori, 2014; 
Howland, 2015; Wilson and Tripp, 2018). It is a full agonist at presynaptic 5-HT1A autoreceptors, where it initially inhibits synthesis and release of 5-HT. Repeated administration of buspirone inhibits the function of 5-HT1A autoreceptors and its feedback control over the synthesis and release of 5-HT (Haleem et al., 2018). Buspirone is also a partial agonist at 5-HT1AR in the hippocampus and frontal cortex, where it is expressed as a heteroreceptor on GABAergic and glutamatergic neurons, and helps attenuate dysfunctional serotonergic transmission in depressed patients (Celada et al., 2013). Our previous work found that buspirone injected to pregnant rat dams that were stressed during pregnancy, attenuated the inflammatory pain response in the formalin test in the offspring of those dams (Butkevich and Vershinina, 2001).

The formalin test is widely used for assessment of antinociceptive effect of the drugs and induces reproducible and quantifiable pain behavior in two distinct phases with an interphase between them (Dubuisson and Dennis, 1977; Barr, 1998). The first phase represents acute pain and is mediated in part by AMPA receptors whereas the second phase is thought to be more inflammatory and is mediated in part by NMDA receptors. The interphase is a period of dampened pain and is a transition between these two phases and may be mediated by descending inhibition from medullary sites to the spinal cord dorsal horn (Shields et al., 2010; Fischer et al., 2014, 2015; Ishikura et al., 2015; Urien et al., 2017). The formalin test is often used to study the different mechanisms of analgesia induced by various new drugs and the acute to chronic pain transition (Price et al., 2018; Zhang et al., 2018).

Most studies of prenatal exposure on behavior have so far focused on male offspring. Nonetheless, it is essential to include individuals of both sexes in research studies, especially given the sex differences in psychological disorders (Aloisi, 2017; Kundakovic and Jaric, 2017; Gemmel et al., 2019). Data on sex differences in response to SSRIs for the management of chronic pain are limited. We included rats of both sexes in our investigations to determine better whether mechanisms responsible for the effects of fluoxetine and buspirone are sex-specific, which is important for subsequent drug development. Previously, we showed that the chronic administration of fluoxetine to pregnant rat dams that were not stressed during pregnancy did not alter formalin-induced pain behavior or the level of depressive-like behavior in the forced swim test in adolescence (Butkevich and Mikhailenko, 2018). In the present study, we injected the drugs to pregnant rat dams stressed during pregnancy. In view of the questions raised in the literature cited above, the present study compared the prenatal effects of a combination of fluoxetine and buspirone and of each drug alone on basal thermal pain, inflammatory pain-like behavior, and affective behavior. Based on the available clinical literature, we hypothesized that the prenatal effect of the combination of fluoxetine and buspirone would be more effective than of fluoxetine or buspirone alone in altering pain- and depressive-like behaviors of the offspring of dams that were exposed to prenatal stress. We tested this hypothesis in peri-adolescent male and female rats, during an important developmental epoch in which depression is often first evidenced and an age that we have previously studied (Butkevich and Vershinina, 2001; Butkevich et al., 2017).

\section{MATERIALS AND METHODS}

\section{Animals}

All experimental procedures were approved by the Local Ethics Committee for Animal Experiments of the I. P. Pavlov Institute of Physiology, Russian Academy of Sciences (St. Petersburg, Russia) and followed the guidelines published by the Committee for Research and Ethical Issues of the IASP on ethical standards for investigations of experimental pain in animals. Sixty-seven adult female and 33 male Wistar rats (180-220 and 270-300 g, respectively) were obtained from the vivarium of the I.P. Pavlov Institute of Physiology. The work was performed on animals from the biocollection of Pavlov Institute of Physiology of the Russian Academy of Sciences. After 2 days of adapting to new quarters, the rats were mated, and a vaginal smear was examined next morning to verify insemination. The days of insemination and birth were considered as gestational day (GD) 0 and postnatal day (PD) 0 , respectively. Pregnant dams were housed four per cage, then individually after the 17th day of pregnancy. All animals were maintained under standard conditions ( $12 \mathrm{~h}$ light, $12 \mathrm{~h}$ dark, lights on at 08:00, $20-22^{\circ} \mathrm{C}$ ) in standard plastic rat cages with food and water available ad libitum.

\section{Experimental Design}

On GD nine rat dams were randomly assigned to the following groups with daily morning intraperitoneal injections until delivery: (1) vehicle + vehicle (labeled "V"), $0.5 \mathrm{ml} / \mathrm{kg}, n=21$ ); (2) vehicle + fluoxetine (labeled “F”), Sigma, $10 \mathrm{mg} / \mathrm{kg}, n=14$ ); (3) vehicle + buspirone (labeled "B"), Sigma, $3.5 \mathrm{mg} / \mathrm{kg}, n=11$ ); or (4) combination of fluoxetine and buspirone (labeled "FB") at the doses listed above, $n=21$ ). The doses of buspirone and fluoxetine were chosen according to the literature and our previous studies (Kim and Druse, 1996; Mikhailenko and Butkevich, 2019). It should be noted that at the dose used here, the existing literature indicates that buspirone does not alter dopamine or norepinephrine function (Cimino et al., 1983). Nine dams of the control group (V) were unstressed during pregnancy ("PNS"). All other rats were exposed to restraint stress from GD 15 to delivery. Stress during pregnancy in rodents (prenatal stress, "PS") is thought to be a model of maternal depression risk (Weinstock, 2008, 2017). For restraint stress, each dam was placed in a prone position in a cylinder, which was adjusted individually to the size of each pregnant dam, such that her movements were sharply restricted. This was done an hour twice daily, once in the morning (between 09.00 and 13.00) and once in the evening (between 14.00 and 19.00) in bright light. Dams were checked for the birth of litters twice daily at $9 \mathrm{AM}$ and $7 \mathrm{PM}$. On PD 1, litters were culled to four males and four females. There were the following experimental groups of male and female rat offspring 
respectively: V-PNS $n=9, n=9$, V-PS $n=12, n=11$, F-PS $n=14, n=12$, B-PS $n=11, n=9$, FB-PS $n=21, n=14$. One male and one female were taken from each litter $(\mathrm{V}$ PNS, V-PS, F-PS, B-PS, FB-PS) for behavioral experiments and corticosterone analysis. The remaining animals were used for other studies.

\section{Behavioral Tests}

When the rats were 25 days of age, basal pain sensitivity in one male and one female from each litter which was selected for experiments in this study was measured in the hot plate test. After that these animals were marked for identification. Weaning was carried out after testing in the hot plate in the rats of all the groups. Males and females from each litter were placed together in the cage without the dam until the end of the experiments. Next day, the inflammatory pain responses were evaluated in the formalin test. Three days later, depression-like behavior was evaluated in the forced swim test.

\section{Hot-Plate (HP) Test}

A rat was placed on a metal surface maintained at $55^{\circ} \mathrm{C}$ and the latency for nociceptive responses was measured (shaking or licking the hind paw). To prevent tissue damage, we terminated the test if there was no response after $30 \mathrm{~s}$. The response latency was averaged from three trials with $10 \mathrm{~min}$ intervals between each trial. The testing apparatus was thoroughly cleaned between trials.

\section{Formalin Test}

The formalin test produces a very reproducible and quantifiable pain behavior represented by two phases. After plantar injection of formalin $(2.5 \%, 1.0 \mu \mathrm{l})$ into the left hind paw, the rat was placed singly in a chamber $(25 \times 20 \times 10 \mathrm{~cm})$ with transparent glass walls for $60 \mathrm{~min}$. The formalin response consists of flexing, shaking and licking behaviors organized in two phases with the period of the interphase, period of quiescence, between them. The first acute short phase (about $6 \mathrm{~min}$ ) after the formalin injection is thought to arise from direct activation of myelinated and unmyelinated nociceptive afferent fibers. The second tonic phase (about $51 \mathrm{~min}$ ) is considered to result from changes in CNS function induced by neural activity generated during the acute phase and from the developing inflammation caused by the formalin during the tonic phase. The formalin test allows studying mechanisms through which persistent nociception is generated (Dubuisson and Dennis, 1977; Abbott and Guy, 1995; Zhang et al., 2018). We recorded the number of flexes + shakes, organized at the spinal level, and duration of licking reaction, organized at the supraspinal level. We used a computer program specially created for our experiments to record, quantify and analyze the formalininduced pain behaviors. Each 3-min value of flexing + shaking behavior and of licking duration was averaged and analyzed in the first phase (the first two 3-min periods; acute nociception), the interphase (the third 3-min period) and the second phase (the fourth to 20th 3-min periods; inflammatory pain response) of the formalin test, according to the literature (Taylor et al., 1998) and our previously published data (Butkevich et al., 2007). The time-course of formalin-induced pain was plotted for each group of rats.

\section{Forced Swim Test}

Each rat was individually placed into the glass cylinder filled with water (diameter $25 \mathrm{~cm}$, height $60 \mathrm{~cm}, 24^{\circ} \pm 1^{\circ} \mathrm{C}$ ). The time of immobility (the rat only made movements necessary to keep the head above the water) was recorded during the 5-min test. This parameter, characterizing the level of depression, is widely considered a negative index of the animal's ability to cope with stress (Burke et al., 2016). However, over the past few years, there is a trend to interpret the time of immobility rather as the expression of a coping strategy (Molendijk and de Kloert, 2019). We had considered this issue earlier (Mikhailenko et al., 2010). Now, we believe that the use of a varied test battery is necessary to fully characterize depression-like behavior in male and female rats.

\section{Corticosterone Determination}

A basal level of corticosterone and the level of corticosterone in response to forced swimming were determined in separate groups of males aged 25 days (in each group $n=5-7$ ). Basal blood samples were collected by rapid decapitation without anesthesia at $9 \mathrm{AM}$; stress blood samples were collected at $30 \mathrm{~min}$ after the forced swim test. The blood samples were centrifuged, and the plasma was kept at $-20^{\circ} \mathrm{C}$. The content of corticosterone in plasma was determined in duplicate by immune-enzyme analysis, using standard kits ("Xema-Medica Co" Cat No: K210R; Russia); the intra-assay coefficient was 3.8.

\section{Statistical Analyses}

Mixed-model ANOVA's were used to explore the influence of Time (3 min periods), Sex (males, females) and Treatment (vehicle and no stress, vehicle and stress, buspirone and stress, fluoxetine and stress, buspirone + fluoxetine and stress) for the Phase I (first two 3-min periods) and Phase II (the fourth to 20th 3-min periods) separately and a two factor ANOVA (Sex and Treatment) for the Interphase (the third 3-min period). Twofactor ANOVA's were used to explore the influence of Sex and Treatment (vehicle and no stress, vehicle and stress, buspirone and stress, fluoxetine and stress, buspirone + fluoxetine and stress) on the hot plate latency and immobility time in the forced swim test. Prenatal Treatments conducted (vehicle and no stress, vehicle and stress, buspirone and stress, fluoxetine and stress, buspirone + fluoxetine and stress) are the same throughout here. Post hoc comparisons were made with Bonferroni multiple comparisons test. A one-factor ANOVA was conducted to explore the influence of Treatment on basal corticosterone level and corticosterone level after forced swim test, again followed by Bonferroni post hoc tests. Data analysis was carried out with the SPSS Inc. software. The results are expressed as mean \pm standard error of the mean (SEM).

\section{RESULTS}

The chronic administration of fluoxetine during pregnancy did not change the duration of pregnancy in dams, but there was 
a slight decrease in the number of rat pups compared to the number of pups in the control group, as well as a single death both in the newborn rat pups and rat pups during the transition from dam feeding to independent feeding. It is worth noting a similar negative effect on these indicators was also caused by the stressful procedure itself of a chronic prenatal injection of saline. In newborn offspring of both sexes, prenatal administration of fluoxetine caused a slight decrease in body weight compared with the body weight of rats born to mothers with saline and body weight of intact animals, while the administration of buspirone did not cause significant changes in the body weight of newborn rats. At 25 days of age, the body weight of males with prenatal fluoxetine remained lower than that of males with prenatal saline and intact males, whereas there was no difference in body weight between females in the studied groups. All data on the effects of prenatal administration of fluoxetine and buspirone in the

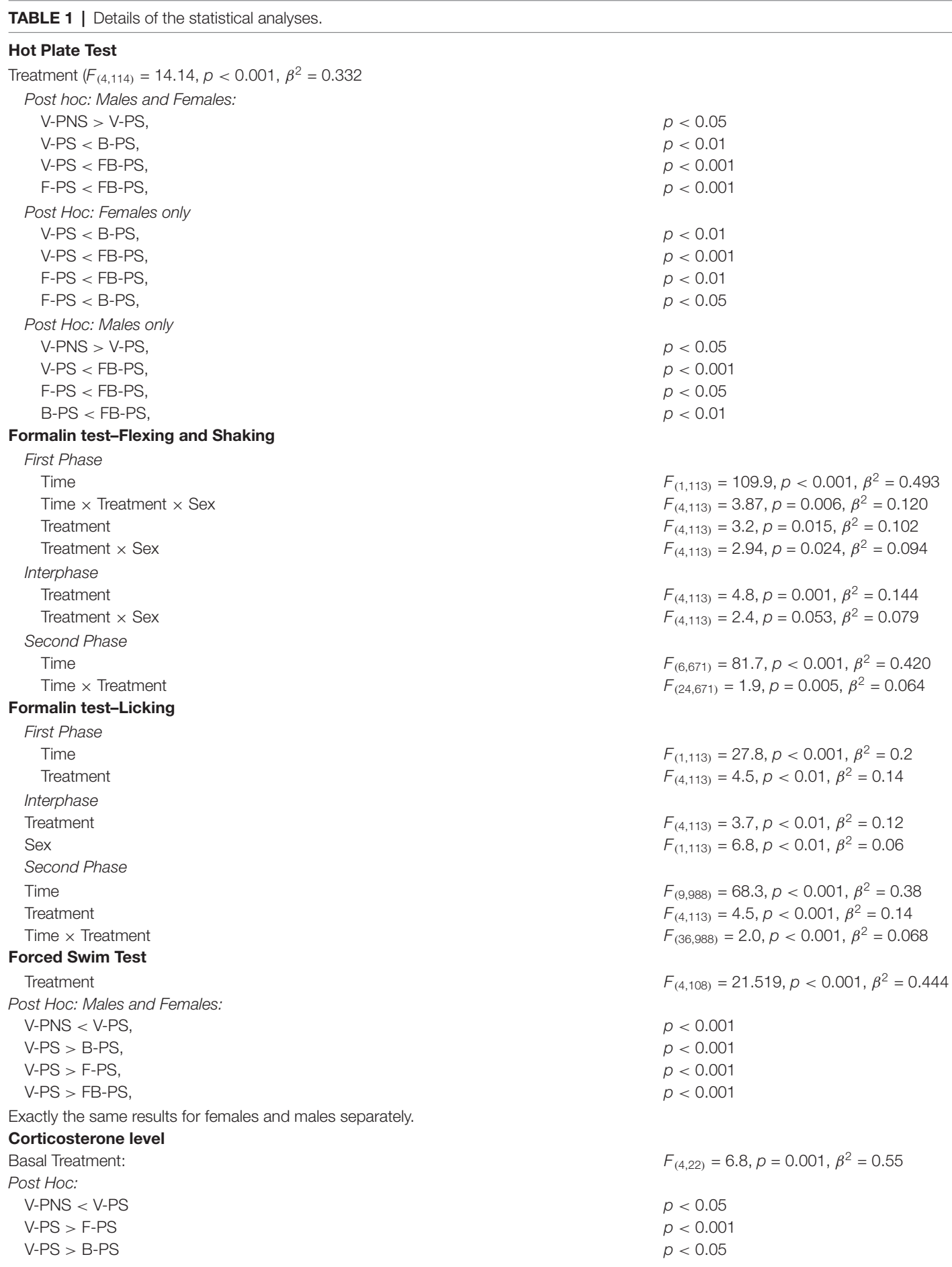


dam and her offspring have been published in our previous articles (Butkevich et al., 2017; Butkevich and Mikhailenko, 2018; Mikhailenko and Butkevich, 2018).

Details of the analyses are in Table $\mathbf{1}$ and summarized below. The results are summarized in schematic form in Table 2.

\section{Hot Plate (HP) Test (Figure 1)}

\section{Thermal Withdrawal Latency (Figure 1)}

Stress alone enhanced thermal nociception significantly in males and females, and this was decreased significantly by buspirone and combination of the drugs in rats of both sexes. The effect of the both drugs combined was greater than that of fluoxetine in prenatally stressed males and females and greater than the effect of buspirone in prenatally stressed males.

\section{Formalin Test (Figures 2, 3, 4)}

Prenatal Stress Effects and Sex Differences (Figure 2)

For flexing and shaking, there were sex differences in responding in the first phase and the interphase, with higher levels of responding in the males than the females (Figures 2A,B). The post hoc analysis of male responses revealed that prenatal stress increased flexing + shaking behavior in the first and the second phases, and the interphase (Figure 2A). There were no significant differences induced by prenatal stress in females in any phase (Figure 2B).

For licking duration, the post hoc analysis revealed that prenatal stress increased licking duration in males only in the second phase compared to non-stressed males (Figure 2C) whereas stressed females showed higher rates of licking than did non-stressed females in the first phase, the interphase and at the peak of the second phase (Figure 2D).

\section{Drug Effects in Prenatally Stressed Rats (Figure 3)}

For flexing and shaking, the post hoc analysis revealed that for males, both drugs and their combination decreased flexing + shaking behavior in the first and the second phases compared with vehicle control males (Figure 3A); in addition, B-PS and FB-PS decreased flexing + shaking behavior in the interphase. In females, neither of the drugs nor their combination significantly changed flexing + shaking behavior (Figure 3B).

For licking duration, the post hoc analysis revealed that in males both drugs and their combination decreased licking duration in the second phase; in addition, B-PS decreased licking in the first phase (Figure 3C). In females, both drugs and their combination decreased licking in the second phase compared vehicle stressed females; also, B-PS decreased licking in the first phase and interphase and FB-PS in the first phase only (Figure 3D).

\section{Comparison Between Drug Effects, Sex Differences (Figure 4)}

For flexing and shaking, the antinociceptive effect of B-PS was greater that of FB-PS in males and females during the interphase (Figures 4A,B), and in females, in the second half of the second phase (Figure 4B). B-PS was more effective than F-PS during the interphase in males and females (Figures $\mathbf{4 A}, \mathbf{B}$ ). Sex differences in flexing + shaking behavior were found in FB-PS rats, in the

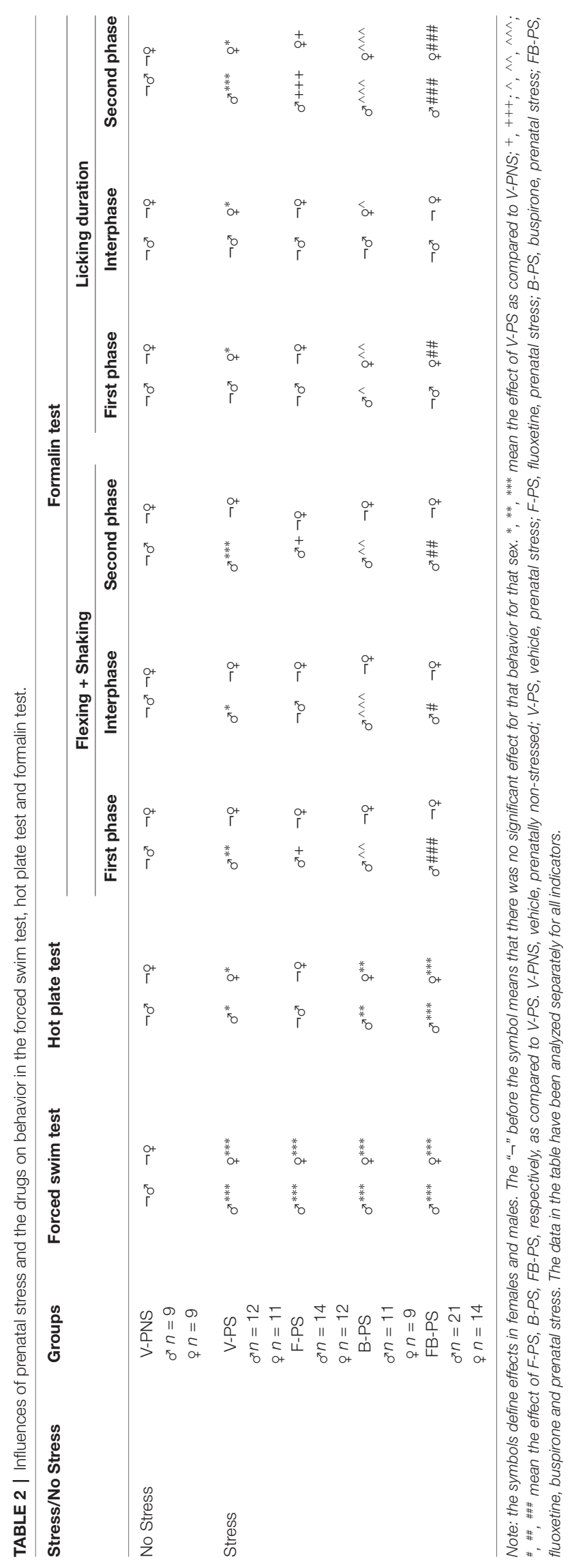


both phases and the interphase (Figure 4B) with a stronger antinociceptive effect in males.

For licking duration, antinociceptive effect of B-PS was greater that of FB-PS in the interphase in males and females (Figures 4C,D), and greater than that of F-PS in the first phase, the interphase and the second phase in females (Figure 4D). The antinociceptive effect of FB-PS was greater that of F-PS in the first phase in females (Figure 4D). Sex differences in licking duration were found in the interphase in F-PS and FB-PS with the stronger antinociceptive effect in males (Figure 4D).

\section{Forced Swim Test (Figure 5)}

For immobility time, there were significant effects of Treatment and post hoc analyses for males and females combined showed that prenatal stress resulted in increased time immobile and that all three drug conditions reduced immobility to control levels. Identical results were found when each sex was analyzed separately. Thus, stress alone increased the time of immobility significantly in males and females, and this was decreased significantly by fluoxetine, buspirone or combination of the drugs in prenatally stressed male and female rats.

\section{Corticosterone Determination (Figure 6)}

For basal corticosterone, there was the main effect of Treatment and post hoc analyses revealing a stress induced increase in basal level of corticosterone in prenatally stressed rats. F-PS and B-PS decreased the basal level of corticosterone below that of the vehicle stressed animals (Figure 6A). Forced swimming increased corticosterone level in stressed rats given fluoxetine, buspirone compared with the basal level of corticosterone in rats with corresponding prenatal injections. There were no significant differences in the level of the hormone between F-PS, B-PS, FBPS, V-PS and V-PNS rats (Figure 6B).

\section{DISCUSSION}

\section{Summary of Findings}

The present study presents novel data that describe the effects of repeated prenatal administration of fluoxetine, buspirone or their combination on pain- and depressive-like behavior that were enhanced by prenatal stress. Prenatal stress disrupts the normal development of the serotonergic system (Van den Hove et al., 2006; Gemmel et al., 2018; Kiryanova et al., 2018; Soares-Cunha et al., 2018), the HPA axis (Weinstock, 1997; Gemmel et al., 2017; Morsi et al., 2018), and the brain morphology (van den Bergh et al., 2018). Likewise, the drugs we used act through the 5-HT1AR (Albert and Fiori, 2014) and likely alter its development (Lauder et al., 2000). Our results demonstrate that prenatal stress increased basal

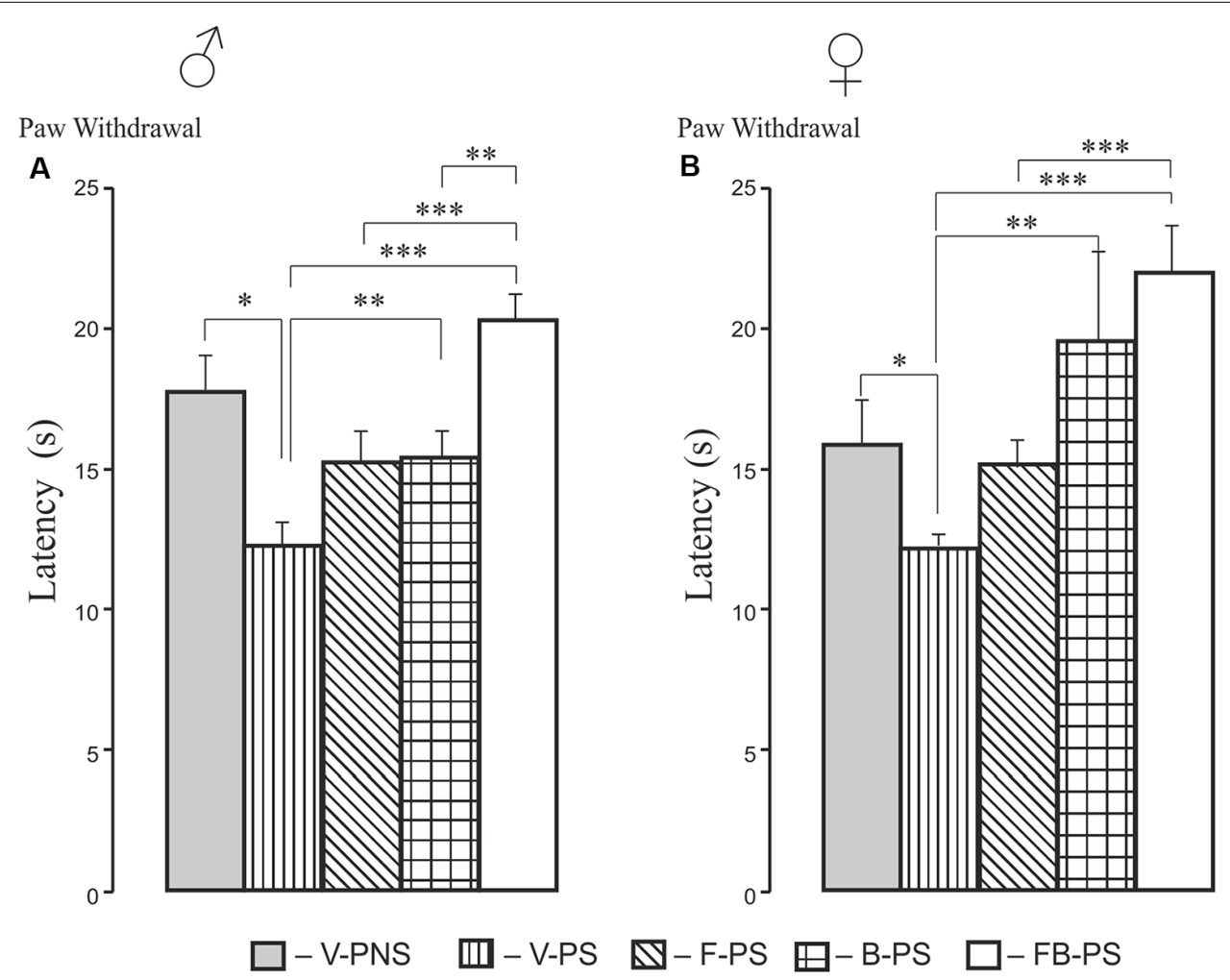

FIGURE 1 | Effects of prenatal stress, fluoxetine, buspirone or fluoxetine and buspirone combination on paw withdrawal latency in the hot plate test in young male (A) and female (B) rats. V-PNS, vehicle without prenatal stress; V-PS, vehicle and prenatal stress; F-PS, fluoxetine and prenatal stress; B-PS, buspirone and prenatal stress; FB-PS, combination of fluoxetine and buspirone and prenatal stress. Vehicle (control), fluoxetine, buspirone or their combination were injected daily to pregnant dams from G9 to G20. Prenatal stress occurred from G15 to G20. ${ }^{*} p<0.05,{ }^{* *} p<0.01,{ }^{* * *} p<0.001$. Data are means \pm one standard error of the mean (SEM). 


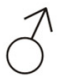

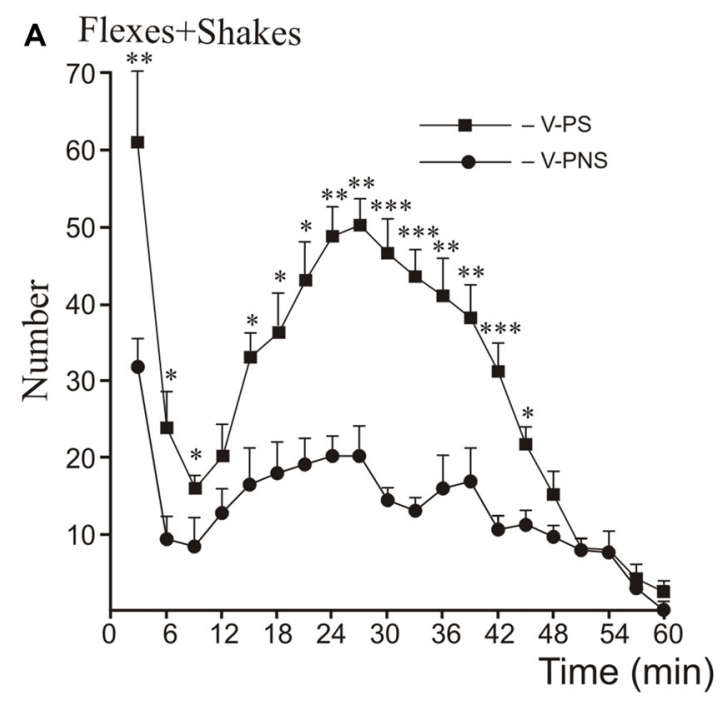

千

B Flexes + Shakes

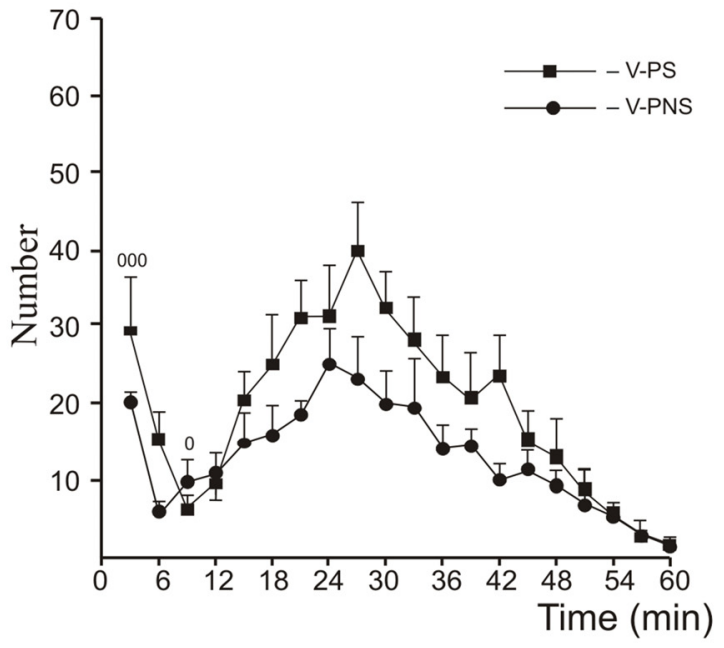

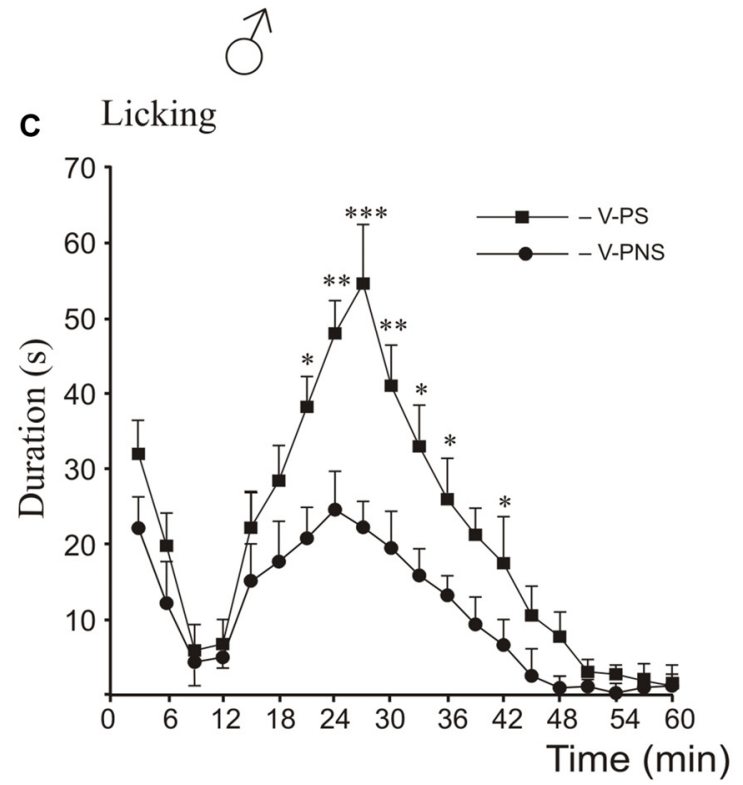

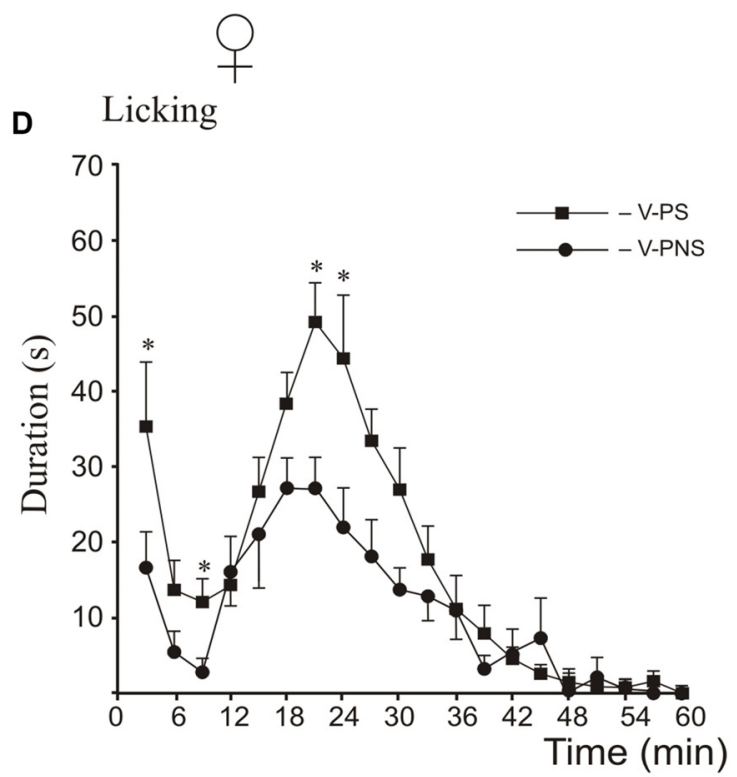

FIGURE 2 | Effects of prenatal stress on the time-course of flexing + shaking behavior (A,B) and licking duration (C,D) in the formalin test during the first phase, the interphase and the second phase in young male (A,C) and female (B,D) rats. V-PNS, vehicle without prenatal stress; V-PS, vehicle and prenatal stress. For prenatal effects: Panels (A,C,D): ${ }^{*} p<0.05,{ }^{* *} p<0.01,{ }^{* * *} p<0.001, \mathrm{~V}-\mathrm{PS}$ vs. V-PNS. Panel (B): no significant differences. For sex differences in flexing and shaking in prenatally stressed young rats (pane/ B): ${ }^{0} p<0.05,{ }^{000} p<0.001$. There were no sex differences for licking. Data are mean \pm one SEM.

thermal pain sensitivity, prolonged formalin-induced pain-like response, and depressive-like behavior in the young rats of both sexes. The time-course of formalin-induced pain showed sexual dimorphism in response to prenatal stress. Prenatal treatment with the antidepressant fluoxetine, the anxiolytic buspirone or their combination eliminated the adverse influences of prenatal stress on pain and depressive-like behavior in male and female rats. For the acute thermal pain assay, for males B-PS and FB-PS reversed the effects of stress with FB-PS being much more effective than either drug alone. For females, the results were similar except that B-PS and FB-PS were equally effective. In the first acute pain phase of the formalin test the stress induced elevated flexing and shaking was reduced equally by all three drug treatments only in males. These treatments had no effect on these behaviors in females. For licking, the acute pain response was decreased in males only by B-PS, whereas in females both B-PS and FB-PS were effective. In the interphase for flexing + shaking and licking behavior, the 

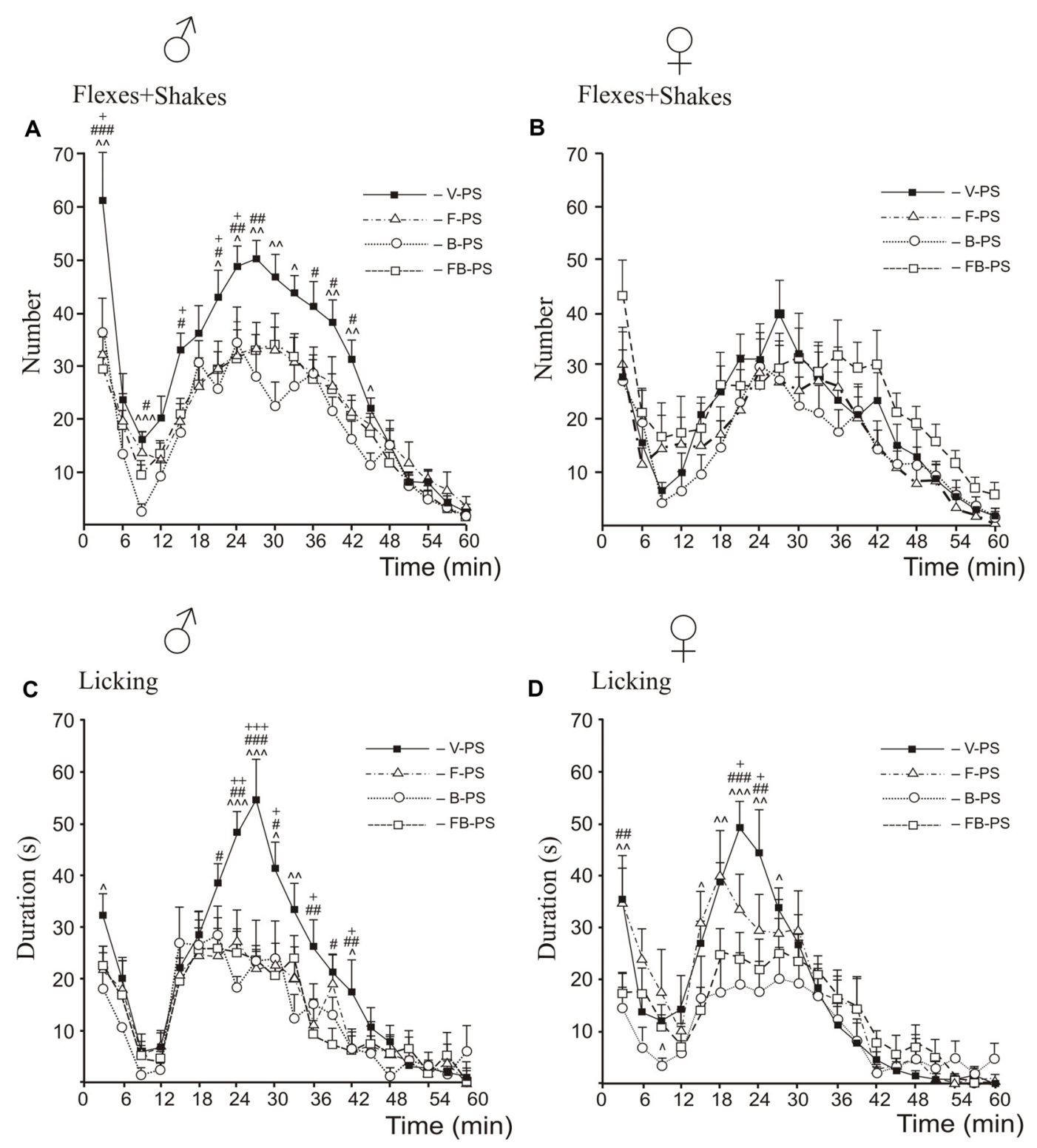

FIGURE 3 | Effects of prenatal stress, fluoxetine, buspirone or fluoxetine and buspirone combination on the time-course of flexing + shaking behavior (A,B) and licking duration (C,D) in the formalin test during the first phase, the interphase and the second phase in young male (A,C) and female (B,D) rats. V-PS, vehicle and prenatal stress; F-PS, fluoxetine and prenatal stress; B-PS, buspirone and prenatal stress; FB-PS, fluoxetine and buspirone combination and prenatal stress. Panels (A,C,D): F-PS vs. V-PS: ${ }^{+} p<0.05,{ }^{++} p<0.01,{ }^{+++} p<0.001$; B-PS vs. V-PS: ${ }^{\wedge} p<0.05, \wedge \wedge<0.01, \wedge \wedge \wedge<0.001$; FB-PS vs. V-PS: ${ }^{\wedge} p<0.05,{ }^{\# \#} p<0.01$, ${ }^{\# \# \#} p<0.001$. Panel (B): no significant differences. Data are mean \pm one SEM.

antinociceptive effect of B-PS dominated that of FB-PS and that of F-PS in the interphase for flexing + shaking behavior in rats of both sexes. In the second, inflammatory phase of the formalin test, stress-induced increases in flexing and shaking and licking were reduced by drug treatment in males and only in licking in females. However, B-PS was more effective than F-PS in reducing licking behavior in all three phases of the formalin test only in females. In the Forced swim test, there was not the expected advantage in effects of the antidepressant combination of FB-PS compared to those of F-PS, in both sexes.

\section{Prenatal Stress Effects}

Prenatal stress increased basal thermal pain sensitivity as evidenced by a decreased the paw withdrawal latency in the hot plate test equally in both male and female rats; these results support our previous data (Mikhailenko and Butkevich, 2019). The time-course of formalin-induced pain in response to prenatal stress, to the contrary, showed marked differences between male and female rats with prenatal stress failing to increase flexing and shaking compared to non-stressed females. In addition, the effect of prenatal stress on flexing + shaking behavior during the first acute phase was more intense in 

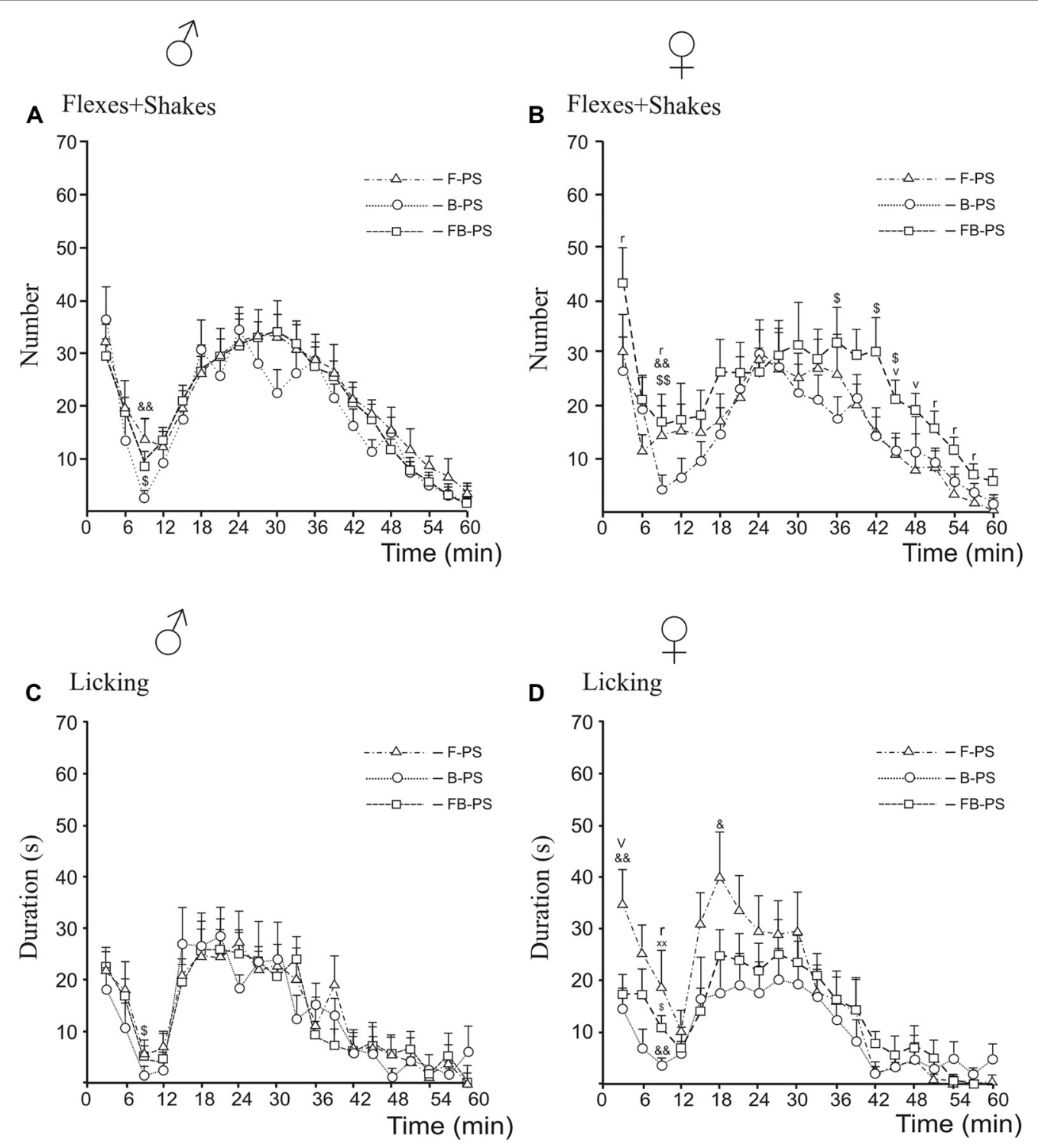

FIGURE 4 | Differences between prenatal effects of fluoxetine, buspirone and fluoxetine and buspirone combination on the time-course of flexing + shaking behavior (A,B) and licking duration (C,D) in the formalin test during the first phase, the interphase and the second phase in young male (A,C) and female (B,D) rats. F-PS, fluoxetine and prenatal stress, B-PS, buspirone and prenatal stress, FB-PS, fluoxetine and buspirone combination and prenatal stress. For all panels: B-PS vs. FB-PS: ${ }^{\$} p<0.05,{ }^{\$} p<0.01$; F-PS vs. B-PS: ${ }^{\$} p<0.05$, ${ }^{\&} \& p<0.01$; F-PS vs. FB-PS: ${ }^{v} p<0.05$. For sex differences in prenatal effects of fluoxetine and fluoxetine and buspirone combination in prenatally stressed young rats (panels B,D): F-PS: ${ }^{x x} p<0.01$; FB-PS: ${ }^{r} p<0.05$. Data are mean \pm one SEM.

males than in females. The increase of the first phase in V-PS males, but not in V-PS females, may be associated with a differential influence of prenatal stress on nociceptors via microglia. According to the current literature, prenatal stress activates microglia, which releases cytokines and chemokines (Cattane et al., 2018), that can directly sensitize nociceptors and thereby directly mediate pain during inflammatory conditions (Cook et al., 2018). There are sex differences in the prenatal development of microglia, which in turn may differentially program of sexual differences in the brain and behavior (Nelson and Lenz, 2017; VanRyzin et al., 2018). These putative mechanisms will require further study.
We also found that in the second tonic phase of the formalin test, prenatal stress increased licking, organized at the supraspinal level, in the rats of both sexes, but flexing + shaking behavior, organized at the spinal level, differed significantly only in males. The second phase in the formalin test is believed to be due to central sensitization of spinal neurons, induced by stimulation of TRPA1 during the first phase, and by an inflammatory response triggered by an "inflammatory soup" consisting of many mediators (serotonin, prostaglandins, IL-1 $\beta$, IL-6 etc.; Basbaum and Jessell, 2000). The interphase and the second phase of formalin-induced pain are also modulated by descending inhibition from the periaqueductal 
<smiles>[CH]</smiles>

A

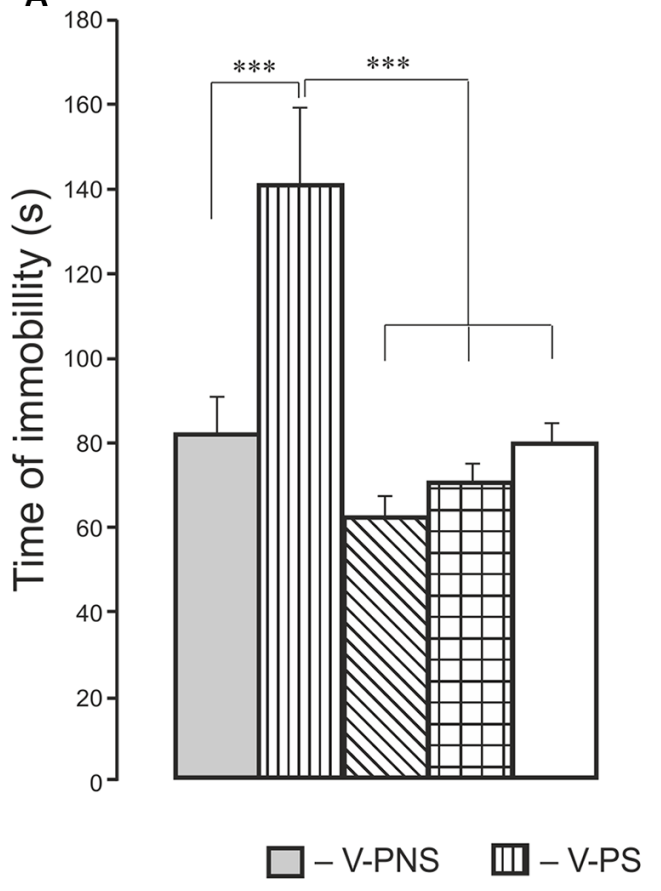

B

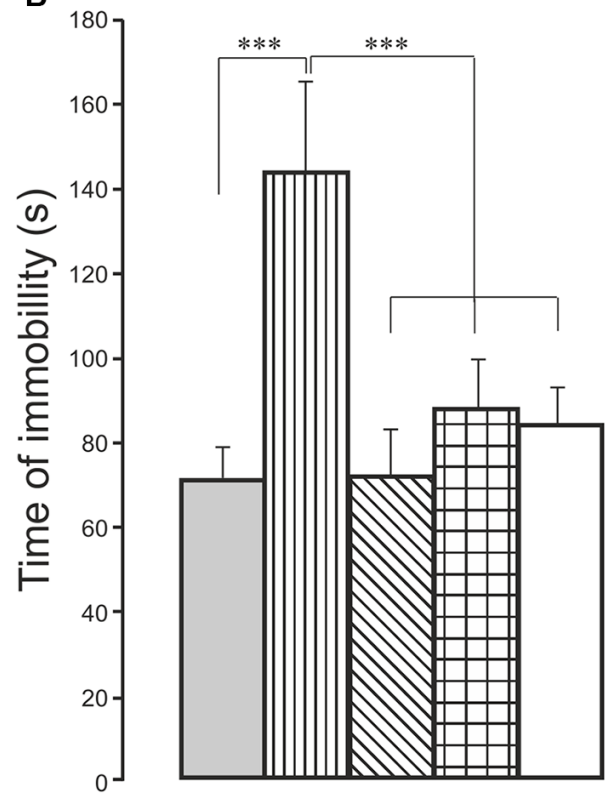

FIGURE 5 | Effects of prenatal stress, fluoxetine, buspirone and their combination on the time of immobility in the forced swim test in young male (A) and female (B) rats. V-PNS, vehicle without prenatal stress (without stress of pregnant dams), V-PS, vehicle and prenatal stress, F-PS, fluoxetine and prenatal stress, B-PS, buspirone and prenatal stress, FB-PS, combination of fluoxetine and buspirone and prenatal stress. ${ }^{* * *} p<0.001$. Data are mean \pm one SEM.

gray (PAG), projecting to the rostral ventromedial medulla (RVM) and subsequently to the spinal cord (Millan, 2002). This constitutes a major mechanism by which pain transmission is modulated (Fields and Basbaum, 1999). These descending pathways from the RVM are the main source of serotonergic inputs to the spinal dorsal horn, and the alteration by prenatal stress of serotonergic system function in a sex-specific manner may explain the different effects of prenatal stress in male and female rats. This hypothesized mechanism is supported by previous findings demonstrating sexual dimorphism in anatomical organization and the functional activation of the PAG-RVM circuit (Loyd and Murphy, 2006).

\section{Effects of Prenatal Drug Treatment}

\section{Thermal Test}

We found that prenatally stressed male and female rats treated with buspirone or combination of the drugs mitigated the effects of prenatal stress in the hot plate test. The antinociceptive effect of FB-PS was significantly greater than that of F-PS alone in both males and females, but there was no significant antinociceptive effect of fluoxetine. There are few existent data on the effects of repeated fluoxetine treatment on pain-like behavior; in non-prenatally stressed adult guinea pigs, there were increased thermal pain thresholds (antinociceptive effect;
Vartazarmian et al., 2005); in prenatally stressed adult male rats, post-operative pain measured as hypersensitivity to mechanical stimuli after hind paw incision at 56 days of age, was normalized by perinatal fluoxetine (Knaepen et al., 2013). In the clinic, perinatal maternal stress increases pain sensitivity in infant children that is ameliorated by prenatally exposure to SSRI's (Oberlander et al., 2005).

\section{Formalin Test}

Although both drugs and their combination attenuated the effects of prenatal stress on formalin-induced pain, there were differences in these effects on the prolonged biphasic response. Importantly, the drugs were effective only when formalininduced pain was altered by prenatal stress. Both the preclinical and clinical data on the antinociceptive effects of fluoxetine in adults are inconsistent. A recent review of the literature concluded that the most likely beneficial use of fluoxetine in nociceptive pain management is for the alleviation of inflammatory pain (Barakat et al., 2018). Fluoxetine does not possess significant analgesia effects on its own (Hamdy et al., 2018). Both studies indicate that if fluoxetine is combined with morphine it does not enhance acute morphine analgesia but rather attenuates opioid tolerance and dependance. This is consistent with the hypothesis that although fluoxetine itself may be a weak or ineffective analgesic, it may modulate enhanced pain 


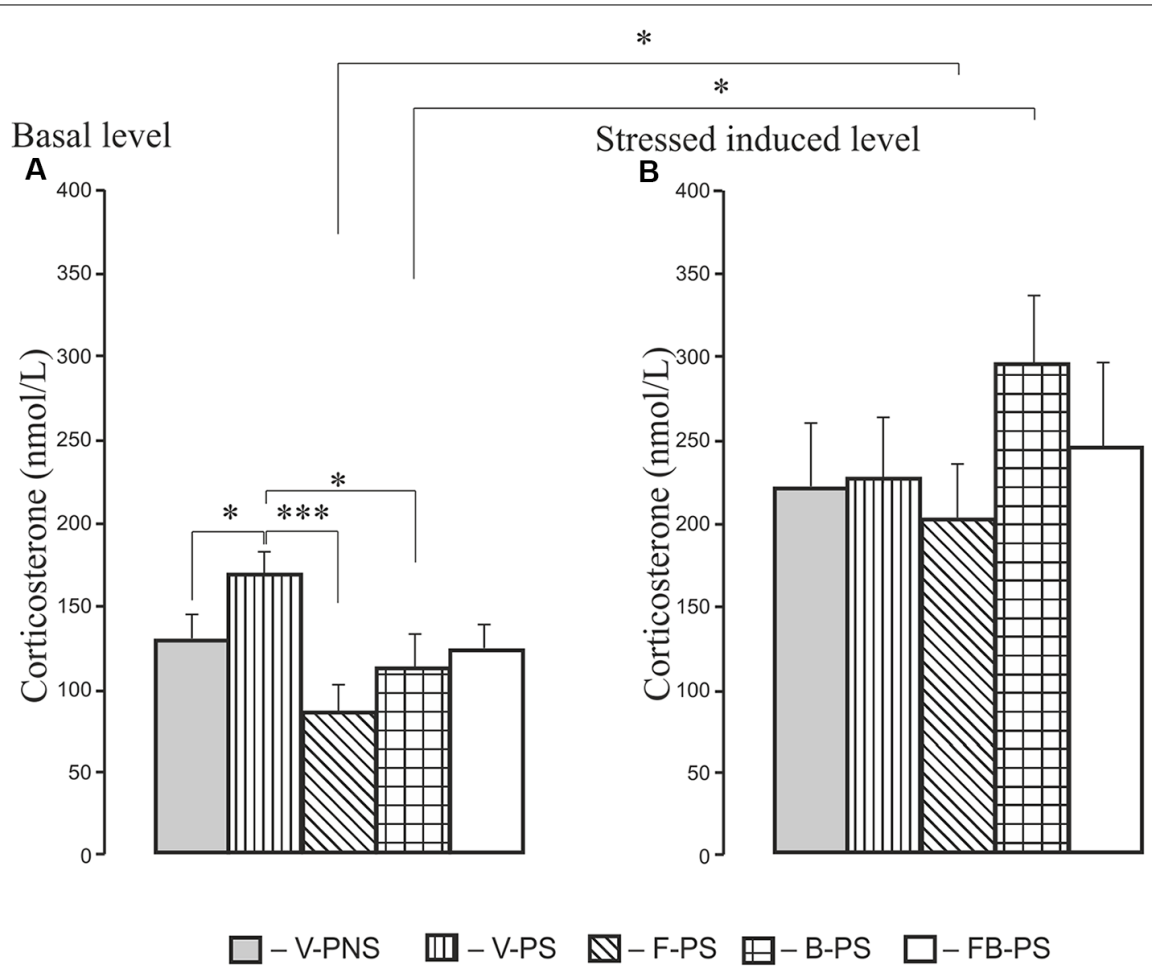

FIGURE 6 | Basal level of corticosterone (A) and level of corticosterone after forced swimming (B) in 25-day-old male rats. For Basal: ${ }^{*} p<0.05,{ }^{* * *} p<0.001$. For Forced Swimming vs. Basal: $* p<0.05$. Data are mean \pm one SEM.

induced by other means perhaps in close conjunction with the descending serotonergic regulation (Basbaum, 1981).

In the test of formalin-induced pain, fluoxetine reduced the total time spent licking and flinching to control levels in the second phase in females but not males (Zammataro et al., 2017). In contrast, F-PS, B-PS and FB-PS decreased flexing + shaking behavior in the second phase in prenatally stressed males but not females. Again, the imposition of stress on the rats altered the effects of fluoxetine on pain in a sex-dependent manner.

Of particular interest, it was the interphase that proved most sensitive to prenatal influence of B-PS as compared with that of FB-PS and F-PS in flexing + shaking and licking behaviors in both sexes (Figure 4). These data suggest that buspirone, to which pregnant stressed dams were exposed, had the greatest effects on the developing descending serotonergic inhibitory system, modulating nociceptive signals in spinal cord dorsal horn neurons. Buspirone is used in the clinic as a serotonergic anxiolytic in patients with increased anxiety and may have antidepressant properties (Savitz et al., 2009; Albert and François, 2010; Kirilly et al., 2015; Haleem et al., 2018), which would be consistent with our data here. Long-term treatment with buspirone downregulates 5-HT1A autoreceptors and enhances serotonergic functions via postsynaptic 5-HT1A heteroreceptors in the hippocampus, cortex and limbic system (Savitz et al., 2009) to mediate the antidepressant actions of 5-HT and reduce pain perception. Negative feedback is speculated to play a major role in the delayed action of SSRI antidepressants because it takes time to overcome the autoreceptor down-regulation.

\section{Potential Mechanisms}

The properties of buspirone as a full agonist of presynaptic and partial agonist of postsynaptic 5-HT1A receptors determine its use in combination with other antidepressants to increase efficacy and reduce side effects in the treatment of depression (Albert and François, 2010; Albert and Fiori, 2014; Stuivenga et al., 2019). When using the combination of fluoxetine and buspirone, the increased extracellular concentration of 5-HT (the action of fluoxetine) occurs without decreased sensitivity of the postsynaptic 5-HT1A receptors due to the ability of the partial agonist buspirone to reduce the function of $5-\mathrm{HT} 1 \mathrm{~A}$ autoreceptors. This results in a greater release of 5-HT by fluoxetine by reducing the negative feedback mechanisms mediated by 5-HT1A autoreceptors and increasing the stimulation of the postsynaptic 5-HT1A receptors (Pierz and Thase, 2014; Wang et al., 2015; Stuivenga et al., 2019).

A comparative analysis of basal plasma corticosterone level in males confirmed the effectiveness of prenatal repeated administration of drugs: prenatal stress increased the basal corticosterone level compared to controls and prenatal drug administration reversed that increase. There were no significant differences in the stressed induced level of the hormone between F-PS, B-PS, FB-PS rats and V-PS and V-PNS rats, probably due to the high reactivity of the HPA axis in response to the severe physical and psycho-emotional stress of forced swimming. Fluoxetine can be immunomodulatory, acting on serotonergic neurons in the $\mathrm{CNS}$ and regulating 
neuroendocrinal signals (Di Rosso et al., 2016). Fluoxetine normalizes the immune function, increasing it when conditions reduced function, but decreasing it under conditions of high function (for example, in prenatally stressed rats). Because of the anti-inflammatory properties of fluoxetine (Valera et al., 2014) and buspirone (Sharifi et al., 2015), we cannot exclude the hypothesis that their behavioral effects as shown here are due to normalization inflammatory cytokines. Cytokines contribute to the restoration of afferent-efferent connections of the raphe nuclei with the PFC and spinal cord, which are involved in the integration of antinociceptive and psychoemotional systems (Wang and Nakai, 1994). If stress during pregnancy has deleterious effects on the fetal immune system (Lasselin et al., 2019), the improvement of the adaptive behaviors studied here in the prenatally stressed rats by prenatal exposure to buspirone, fluoxetine or their combination can be viewed as a manifestation of their protective properties on immune function. Whether these findings will hold true for females remain to be tested.

\section{Sex Differences}

The benefits of FB-PS over F-PS alone were seen in females only in the first acute phase of licking behavior when FB-PS normalized the stress-induced pain response, whereas F-PS had no effect. Considering that fluoxetine and buspirone act via 5HT1AR, these results point to differences in the mechanisms by which they act prenatally on the development of 5-HT1AR. Of particular interest, the antinociceptive effects of FB-PS were greater in males than females in the first phase, the interphase and the second phase for flexing + shaking behaviors and in the interphase in FB-PS and F-PS for licking behavior. Thus, the combined drug treatment of prenatally stressed pregnant dams more effectively attenuated inflammatory pain-like behavior in male offspring than the female offspring. It will be particularly important to extend these findings to post-sexual maturity subjects to understand the interplay between prenatal stress, sex and transitions across preadolescence, adolescence and post-adolescence. It is during this time that the prevalence and risk of psychiatric disease is rapidly changing and when sexually dimorphic chronic pain conditions first emerge (Paus et al., 2008).

Sexual dimorphism found in the prenatally stressed rats in pain-related indices is associated with suppression of the release of testosterone, which itself has an analgesic effect (Edinger and Frye, 2005; Da Silva et al., 2018). The sex steroid hormones estrogens and androgens modulate prenatal and postnatal development of many processes including the nociception, the HPA axis and immune system (Green and McCormick, 2016; Fanton et al., 2017). Differences in the prenatal action of the drugs on inflammatory painful behavior may also be related to the sexual differences in the development of microglia during critical periods prenatally (Nelson and Lenz, 2017). These sex-dependent differences in the course of microglial development may determine the different sensitivity of microglia to the effects of fluoxetine and the combination of the drugs in the two sexes (Schwarz et al., 2012), as the immune system acts as a regulator of sex differences in brain development and behavior (Nelson and Lenz, 2017; VanRyzin et al., 2018; Goldstein et al., 2019). Current genetic studies emphasize that the epigenetic and behavioral effects of prenatal environmental exposures are often found to be sex-specific (Kundakovic and Jaric, 2017). Differences in drug susceptibility, reactions to stress, may be due to polymorphism of the 5-HT1A gene (Albert and Fiori, 2014; Luckhart et al., 2016). These sex differences in 5-HT1A autoreceptor function suggest that different adaptive mechanisms are involved in males and females to regulate 5-HT activity and behavior. Among the transcription factors that suppress the expression of the 5-HT1AR gene in the raphe nuclei is the Deaf- 1 factor transcription regulator, which increases serotonergic tone by suppressing the presynaptic expression of 5-HT1AR and simultaneously stimulating postsynaptic 5-HT1AR (Albert and François, 2010; Albert and Fiori, 2014).

In summary, our results show that the inflammatory pain-like responses organized at the spinal level in young pre-adolescent males are more vulnerable to prenatal stress and more sensitive to prenatal drugs compared to pre-adolescent young females. These results re-emphasize the importance of studying both sexes to study the mechanisms of long-term prenatal influence of drugs. Considering the lack of clinical and experimental data on the effects of antidepressants used to treat depression during pregnancy on the nociceptive system's vulnerability to inflammatory agents in the offspring, the results of this work will be useful for studying the mechanisms of action of the studied drugs and also for predicting analgesics dosing in male and female offspring of mothers exposed to stress and antidepressants during pregnancy.

\section{ETHICS STATEMENT}

All experimental procedures were approved by the Local Ethics Committee for Animal Experiments of the I. P. Pavlov Institute of Physiology, Russian Academy of Sciences (St. Petersburg, Russia) and followed the guidelines published by the Committee for Research and Ethical Issues of the IASP on ethical standards for investigations of experimental pain in animals.

\section{AUTHOR CONTRIBUTIONS}

IB and VM: experimental design. IB, VM and EV: collection of data, conduction of statistical analyses. IB, VM, EV and GB: interpretation and analysis of data, participated in the drafting and revising of the manuscript and reviewed and approved the final submitted manuscript.

\section{FUNDING}

This study was supported by the Russian Foundation for Basic Research (grant no. 17-04-00214-a). GB is supported in part by the James Battaglia Endowed Chair in Pediatric Pain Medicine at the Children's Hospital of Philadelphia. 


\section{ACKNOWLEDGMENTS}

We are grateful to our collaborators Elena Lavrova, Natal'ya Ulanova for their help with behavioral testing. We would like

\section{REFERENCES}

Abbott, F. V., and Guy, E. R. (1995). Effects of morphine, pentobarbital and amphetamine on formalin-induced behaviours in infant rats: sedation versus specific suppression of pain. Pain 62, 303-312. doi: 10.1016/03043959(94)00277-1

Albert, P. R., and Fiori, L. M. (2014). Transcriptional dys-regulation in anxiety and major depression: 5-HT1A gene promoter architecture as a therapeutic opportunity. Curr. Pharm. Des. 20, 3738-3750. doi: $10.2174 / 13816128113196660740$

Albert, P. R., and François, B. L. (2010). Modifying 5-HT1A receptor gene expression as a new target for antidepressant therapy. Front. Neurosci. 4:35. doi: $10.3389 /$ fnins.2010.00035

Aloisi, A. M. (2017). Why we still need to speak about sex differences and sex hormones in pain. Pain Ther. 6, 111-114. doi: 10.1007/s40122-017-0084-3

Andrews, M. H., and Matthews, S. G. (2004). Programming of the hypothalamo-pituitary-adrenal axis: serotonergic involvement. Stress 7 , 15-27. doi: 10.1080/10253890310001650277

Barakat, A., Hamdy, M. N., and Elbadr, M. M. (2018). Uses of fluoxetine in nociceptive pain management: a literature overview. Eur. J. Pharmacol. 829, 12-25. doi: 10.1016/j.ejphar.2018.03.042

Barr, G. A. (1998). Maturation of the biphasic behavioral and heart rate response in the formalin test. Pharmacol. Biochem. Behav. 60, 329-335. doi: 10.1016/s00913057(97)00602-3

Basbaum, A. I. (1981). Descending control of pain transmission: possible serotonergic-enkephalinergic interactions. Adv. Exp. Med. Biol. 133, 177-189. doi: 10.1007/978-1-4684-3860-4_9

Basbaum, A. I., and Jessell, T. M. (2000). "The perception of pain," in Principles of Neural Science, eds E. R. Kandel, J. H. Schwartz and J. M. Jessell (New York, NY: McGraw-Hill Comp), 472-481.

Berrocoso, E., and Mico, J. A. (2009). Role of serotonin 5-HT1A receptors in the antidepressant-like effect and the antinociceptive effect of venlafaxine in mice. Int. J. Neuropsychopharmacol. 12, 61-71. doi: 10.1017/s1461145708008766

Bittle, J., and Stevens, H. E. (2018). The role of glucocorticoid, interleukin$1 \beta$ and antioxidants in prenatal stress effects on embryonic microglia. J. Neuroinflammation 15:44. doi: 10.1186/s12974-018-1079-7

Burke, N. N., Coppinger, J., Deaver, D. R., Roche, M., Finn, D. P., and Kelly, J. (2016). Sex differences and similarities in depressive- and anxiety-like behaviour in the Wistar-Kyoto rat. Physiol. Behav. 167, 28-34. doi: 10.1016/j. physbeh.2016.08.031

Butkevich, I. P., Barr, G. A., and Vershinina, E. A. (2007). Sex differences in formalin-induced pain in prenatally stressed infant rats. Eur. J. Pain 11, 888-894. doi: 10.1016/j.ejpain.2007.02.001

Butkevich, I. P., and Mikhailenko, V. A. (2018). Effect of fluoxetine in prenatal period on nociceptive system reactivity and psychoemotional behavior in young female rats. Bull. Exp. Biol. Med. 165, 209-212. doi: 10.1007/s10517-0184131-9

Butkevich, I. P., Mikhailenko, V. A., Vershinina, E. A., Aloisi, A. M., and Barr, G. A. (2017). Long-term effects of chronic buspirone during adolescence reduce the adverse influences of neonatal inflammatory pain and stress on adaptive behavior in adult male rats. Front. Behav. Neurosci. 26:11. doi: 10.3389/fnbeh.2017.00011

Butkevich, I. P., and Vershinina, E. A. (2001). Prenatal stress alters time characteristics and intensity of formalin-induced pain responses in juvenile rats. Brain Res. 915, 88-93. doi: 10.1016/s0006-8993(01)02819-0

Carr, G. V., and Lucki, I. (2011). The role of serotonin receptor subtypes in treating depression: a review of animal studies. Psychopharmacology 213, 265-287. doi: $10.1007 / \mathrm{s} 00213-010-2097-\mathrm{z}$

Cattane, N., Richetto, J., and Cattaneoa, A. (2018). Prenatal exposure to environmental insults and enhanced risk of developing schizophrenia and to thank Ekaterina Tul'kova the collaborator of laboratory of regulation of neural function of brain (Chief Dr Sci. Elena Rybnikova) for the analysis of the corticosterone level in the blood plasma.

autism spectrum disorder: focus on biological pathways and epigenetic mechanisms. Neurosci. Biobehav. Rev. doi: 10.1016/j.neubiorev.2018.07.001 [Epub ahead of print].

Celada, P., Puig, M. V., and Artigas, F. (2013). Serotonin modulation of cortical neurons and networks. Front. Integr. Neurosci. 7:25. doi: 10.3389/fnint.2013. 00025

Chaouloff, F. (2000). Serotonin, stress and corticoids. J. Psychopharmacol. 14, 139-151. doi: 10.1177/026988110001400203

Cimino, M., Ponzio, F., Achilli, G., Vantini, G., Perego, C., Algeri, S., et al. (1983). Dopaminergic effects of buspirone, a novel anxiolytic agent. Biochem. Pharmacol. 32, 1069-1074. doi: 10.1016/0006-2952(83)90627-5

Cook, A. D., Christensen, A. D., Tewari, D., McMahon, S. B., and Hamilton, J. A. (2018). Immune cytokines and their receptors in inflammatory pain. Trends Immunol. 39, 240-255. doi: 10.1016/j.it.2017.12.003

Da Silva, J. T., Zhang, Y., Asgar, J., Ro, J. Y., and Seminowicz, D. A. (2018). Diffuse noxious inhibitory controls and brain networks are modulated in a testosterone-dependent manner in Sprague Dawley rats. Behav. Brain Res. 349, 91-97. doi: 10.1016/j.bbr.2018.04.055

Dharmshaktu, P., Tayal, V., and Kalra, B. S. (2012). Efficacy of antidepressants as analgesics: a review. J. Clin. Pharmacol. 52, 6-17. doi: $10.1177 / 0091270010394852$

Di Rosso, M. E., Palumbo, M. L., and Genaro, A. M. (2016). Immunomodulatory effects of fluoxetine: a new potential pharmacological action for a classic antidepressant drug? Pharmacol. Res. 109, 101-107. doi: 10.1016/j.phrs.2015. 11.021

Dubuisson, D., and Dennis, S. G. (1977). The formalin test: a quantitative study of the analgesic effects of morphine, meperidine, and brain stimulation in rats and cats. Pain 4, 161-174. doi: 10.1016/0304-3959(77)90130-0

Edinger, K. L., and Frye, C. A. (2005). Testosterone's anti-anxiety and analgesic effects may be due in part to actions of its $5 \alpha$-reduced metabolites in the hippocampus. Psychoneuroendocrinology 30, 418-430. doi: 10.1016/j.psyneuen. 2004.11.001

Entringer, S., Buss, C., and Wadhwa, P. D. (2015). Prenatal stress, development, health and disease risk: a psychobiological perspective-2015 Curt Richter award winner. Psychoneuroendocrinology 62, 366-375. doi: 10.1016/j.psyneuen.2015. 08.019

Ewing, G., Tatarchuk, Y., Appleby, D., and Kim, D. (2015). Placental transfer of antidepressant medications: implications for postnatal adaptation syndrome. Clin. Pharmacokinet. 54, 359-370. doi: 10.1007/s40262-014-0233-3

Fanton, L. E., Macedo, C. G., Torres-Chavez, K. E., Fischer, L., and Tambeli, C. H. (2017). Activational action of testosterone on androgen receptors protects males preventing temporomandibular joint pain. Pharmacol. Biochem. Behav. 152, 30-35. doi: 10.1016/j.pbb.2016.07.005

Fields, H. L., and Basbaum, A. I. (1999). "Central nervous system mechanisms of pain modulation," in Textbook of Pain, eds P. D. Wall and R. E. Melzack (London: Churchill Livingstone), 309-329.

Fischer, M., Carli, G., Raboisson, P., and Reeh, P. (2014). The interphase of the formalin test. Pain 155, 511-521. doi: 10.1016/j.pain.2013.11.015

Fischer, M. J., Soller, K. J., Sauer, S. K., Kalucka, J., Veglia, G., and Reeh, P. W. (2015). Formalin evokes calcium transients from the endoplasmatic reticulum. PLoS One 10:e0123762. doi: 10.1371/journal.pone.0123762

Gemmel, M., De Lacalle, S., Mort, S. C., Hill, L. A., Charlier, T. D., and Pawluski, J. L. (2019). Perinatal fluoxetine has enduring sexually differentiated effects on neurobehavioral outcomes related to social behaviors. Neuropharmacology 144, 70-81. doi: 10.1016/j.neuropharm.2018.10.009

Gemmel, M., Hazlett, M., Bögi, E., De Lacalle, S., Hill, L. A., Kokras, N., et al. (2017). Perinatal fluoxetine effects on social play, the HPA system and hippocampal plasticity in pre-adolescent male and female rats: interactions with pre-gestational maternal stress. Psychoneuroendocrinology 84, 159-171. doi: 10.1016/j.psyneuen.2017.07.480 
Gemmel, M., Kokras, N., Dalla, C., and Pawluski, J. L. (2018). Perinatal fluoxetine prevents the effect of pre-gestational maternal stress on 5-HT in the PFC, but maternal stress has enduring effects on $\mathrm{mPFC}$ synaptic structure in offspring. Neuropharmacology 128, 168-180. doi: 10.1016/j.neuropharm.2017.10.009

Giordano, J., and Rogers, L. (1992). Putative mechanisms of buspirone-induced antinociception in the rat. Pain 50, 365-372. doi: 10.1016/0304-3959(92) 90042-a

Goldstein, J. M., Hale, T., Foster, S. L., Tobet, S. A., and Handa, R. J. (2019). Sex differences in major depression and comorbidity of cardiometabolic disorders: impact of prenatal stress and immune exposures. Neuropsychopharmacology 44, 59-70. doi: 10.1038/s41386-018-0146-1

Granados-Soto, V., Argüelles, C. F., Rocha-González, H. I., Godínez-Chaparro, B., Flores-Murrieta, F. J., and Villalón, C. M. (2010). The role of peripheral 5-HT1A, 5-HT1B, 5-HT1D, 5-HT1E and 5-HT1F serotonergic receptors in the reduction of nociception in rats. Neuroscience $165,561-568$. doi: 10.1016/j. neuroscience.2009.10.020

Green, M. R., and McCormick, C. M. (2016). Sex and stress steroid in adolescence: gonadal regulation of the hypothalamicppituitary-adrenal axis in the rat. Gen. Comp. Endocrinol. 234, 110-116. doi: 10.1016/j.ygcen.2016.02.004

Haleem, D. J., Nawaz, S., and Salman, T. (2018). Dose related effects of buspirone on pain, learning/memory and food intake. Regul. Toxicol. Pharmacol. 99, 182-190. doi: 10.1016/j.yrtph.2018.09.017

Hamdy, M. M., Elbadr, M. M., and Barakat, A. (2018). Fluoxetine uses in nociceptive pain management: a promising adjuvant to opioid analgesics. Fundam. Clin. Pharmacol. 32, 532-546. doi: 10.1111/fcp.12383

Hartman, S., and Belsky, J. (2018). Prenatal stress and enhanced developmental plasticity. J. Neural Transm. 125, 1759-1779. doi: 10.1007/s00702-018-1926-9

Howland, R. H. (2015). Buspirone: back to the Future. J. Psychosoc. Nurs. Ment. Health Serv. 53, 21-24. doi: 10.3928/02793695-20151022-01

Huizink, A. C., and de Rooij, S. R. (2018). Prenatal stress and models explaining risk for psychopathology revisited: generic vulnerability and divergent pathways. Dev. Psychopathol. 30, 1041-1062. doi: 10.1017/s095457941 8000354

Ishikura, T., Suzuki, H., Shoguchi, K., Koreeda, Y., Aritomi, T., Matsuura, T., et al. (2015). Possible involvement of TRPV1 and TRPV4 in nociceptive stimulationinduced nocifensive behavior and neuroendocrine response in mice. Brain Res. Bull. 118, 7-16. doi: 10.1016/j.brainresbull.2015.08.004

Kaihola, H., Yaldir, F. G., Hreinsson, J., Hörnaeus, K., Bergquist, J., Olivier, J. D. A., et al. (2016). Effects of fluoxetine on human embryo development. Front. Cell. Neurosci. 10:160. doi: 10.3389/fncel.2016.00160

Kim, J. A., and Druse, M. J. (1996). Protective effects of maternal buspirone treatment on serotonin reuptake sites in ethanol-exposed offspring. Dev. Brain Res. 92, 190-198. doi: 10.1016/0165-3806(96)00015-6

Kirilly, E., Gonda, X., and Bagdy, G. (2015). Antidepressants, stressors and the serotonin 1A receptor. Neuropsychopharmacol. Hung. 17, 81-89.

Kiryanova, V., McAllister, B. B., and Dyck, R. H. (2013). Long-term outcomes of developmental exposure to fluoxetine: a review of the animal literature. Dev. Neurosci. 35, 437-439. doi: 10.1159/000355709

Kiryanova, V., Meunier, S. J., and Dyck, R. H. (2017). Behavioural outcomes of adult female offspring following maternal stress and perinatal fluoxetine exposure. Behav. Brain Res. 331, 84-91. doi: 10.1016/j.bbr.2017.05.029

Kiryanova, V., Smith, V. M., Antle, M. C., and Dyck, R. H. (2018). Behavior of adult $5-\mathrm{HT} 1_{A}$ receptor knockout mice exposed to stress during prenatal development. Neuroscience 371, 16-28. doi: 10.1016/j.neuroscience.2017. 11.039

Knaepen, L., Pawluski, J. L., Patijn, J., Kleef, M., Nibboel, D., and Joosten, E. A. (2014). Perinatal maternal stress and serotonin signaling: effects on pain sensitivity in offspring. Dev. Psychobiol. 56, 885-896. doi: 10.1002/dev.21184

Knaepen, L., Rayen, I., Charlier, T. D., Fillet, M., Houbart, V., van Kleef, M., et al. (2013). Developmental fluoxetine exposure normalizes the long- term effects of maternal stress on post-operative pain in Sprague-Dawley rat offspring. PLoS One 8:e57608. doi: 10.1371/journal.pone.0057608

Kundakovic, M., and Jaric, I. (2017). The epigenetic link between prenatal adverse environments and neurodevelopmental disorders. Genes 8:E104. doi: 10.3390/genes8030104

Lacivita, E., Leopoldo, M., Berardi, F., and Perrone, R. (2008). 5-HT1A receptor, an old target for new therapeutic agents. Curr. Top. Med. Chem. 8, 1024-1034. doi: $10.2174 / 156802608785161385$
Lasselin, J., Schedlowski, M., Lekander, M., and Hadamitzky, M. (2019). Editorial: clinical relevance of the immune-to-brain and brain-to-immune communications. Front. Behav. Neurosci. 12:336. doi: 10.3389/fnbeh.2018. 00336

Lauder, J. M. (1990). Ontogeny of the serotonergic system in the rat: serotonin as a developmental signal. Ann. N Y Acad. Sci. 600, 297-313. doi: 10.1111/j.17496632.1990.tb16891.x

Lauder, J. M., Liu, J., and Grayson, D. R. (2000). In utero exposure to serotonergic drugs alters neonatal expression of 5-HT(1A) receptor transcripts: a quantitative RT-PCR study. Int. J. Dev. Neurosci. 18, 171-176. doi: 10.1016/s0736-5748(99)00085-4

Lin, T., Dang, S., Su, Q., Zhang, H., Zhang, J., Zhang, L., et al. (2018). The impact and mechanism of methylated metabotropic glutamate receptors 1 and 5 in the hippocampus on depression-like behavior in prenatal stress offspring rats. J. Clin. Med 7:E117. doi: 10.3390/jcm70 60117

Liu, W., Ge, T., Leng, Y., Pan, Z., Fan, J., Yang, W., et al. (2017). The role of neural plasticity in depression: from hippocampus to prefrontal cortex. Neural Plast. 2017:6871089. doi: 10.1155/2017/6871089

Loyd, D. R., and Murphy, A. Z. (2006). Sex differences in the anatomical and functional organization of the periaqueductal gray-rostral ventromedial medullary pathway in the rat: a potential circuit mediating the sexually dimorphic actions of morphine. J. Comp. Neurol. 496, 723-738. doi: 10.1002/cne.20962

Luckhart, C., Philippe, T. J., Le François, B., Vahid-Ansari, F., Geddes, S. D., Béique, J. C., et al. (2016). Sex-dependent adaptive changes in serotonin-1A autoreceptor function and anxiety in Deaf1-deficient mice. Mol. Brain 9:77. doi: 10.1186/s13041-016-0254-y

Mikhailenko, V. A., and Butkevich, I. P. (2018). Prenatal effect of fluoxetine on nociceptive system reactivity and psychoemotional behavior of young female and male rats. J. Evol. Biochem. Physiology 54, 322-331. doi: 10.1134/S002209 3018040099

Mikhailenko, V. A., and Butkevich, I. P. (2019). Prenatal stimulation of $5-\mathrm{HT}_{1 A}$ receptors improves adaptive behavior in prenatally stressed rats. Bull. Exp. Biol. Med. 166, 306-309. doi: 10.1007/s10517-01904338-x

Mikhailenko, V. A., Butkevich, I. P., Vershinina, E. A., and Semenov, P. O. (2010). Interrelationship between measures of pain reactions in inflammation and levels of depression in prenatally stressed rat pups. Neurosci. Behav. Physiol. 40, 179-184. doi: 10.1007/s11055-009-9241-4

Millan, M. J. (2002). Descending control of pain. Prog. Neurobiol. 66, 355-474. doi: 10.1016/S0301-0082(02)00009-6

Molendijk, M. L., and de Kloert, E. R. (2019). Coping with the forced swim stressor: current state-of-the-art. Behav. Brain Res. 364, 1-10. doi: 10.1016/j.bbr. 2019.02.005

Morsi, A., DeFranco, D., and Witchel, S. F. (2018). The hypothalamicpituitary-adrenal axis and the fetus. Horm. Res. Paediatr. 89, 380-387. doi: $10.1159 / 000488106$

Nejatbakhsh, M., Saboory, E., and Bagheri, M. (2018). Effect of prenatal stress on $\alpha 5 \mathrm{GABA}_{A}$ receptor subunit gene expression in hippocampus and pilocarpine induced seizure in rats. Int. J. Dev. Neurosci. 68, 66-71. doi: 10.1016/j.ijdevneu. 2018.05.003

Nelson, L. H., and Lenz, K. H. (2017). The immune system as a novel regulator of sex differences in brain and behavioral development. J. Neurosci. Res. 95, 447-461. doi: 10.1002/jnr.23821

Oberlander, T. F., Grunau, R. E., Fitzgerald, C., Papsdorf, M., Rurak, D., and Riggs, K. W. (2005). Pain reactivity in 2-month-old infants after prenatal and postnatal serotonin reuptake inhibitor medication exposure. Pediatrics 115 , 411-425. doi: 10.1542/peds.2004-0420

Patel, T. D., and Zhou, F. C. (2005). Ontogeny of 5-HT1A receptor expression in the developing hippocampus. Brain Res. Dev. 157, 42-57. doi: 10.1016/j. devbrainres.2005.03.006

Paus, T., Keshavan, M., and Giedd, J. N. (2008). Why do many psychiatric disorders emerge during adolescence? Nat. Rev. Neurosci. 9, 947-957. doi: $10.1038 / \mathrm{nrn} 2513$

Pavlaković, G., Tigges, J., and Crozier, T. A. (2009). Effect of buspirone on thermal sensory and pain thresholds in human volunteers. BMC Clin. Pharmacol 9:12. doi: $10.1186 / 1472-6904-9-12$ 
Pawluski, J. L., and Gemmel, M. (2018). Perinatal SSRI medications and offspring hippocampal plasticity: interaction with maternal stress and sex. Hormones 17, 15-24. doi: 10.1007/s42000-018-0011-y

Pierz, K. A., and Thase, M. E. (2014). A review of vilazodone, serotonin, and major depressive disorder. Prim. Care Companion CNS Disord. 16:13r01554. doi: 10.4088/pcc.13r01554

Pohland, R. C., Byrd, T. K., Hamilton, M., and Koons, J. R. (1989). Placental transfer and fetal distribution of fluoxetine in the rat. Toxicol. Appl. Pharmacol. 98, 198-205. doi: 10.1016/0041-008x(89)90225-1

Popova, N. K., and Naumenko, V. S. (2013). 5-HT1A receptor as a key player in the brain 5-HT system. Rev. Neurosci. 24, 191-204. doi: 10.1515/revneuro2012-0082

Price, T. J., Basbaum, A. I., Bresnahan, J., Chambers, J. F., De Koninck, Y., Edwards, R. R., et al. (2018). Transition to chronic pain: opportunities for novel therapeutics. Nat. Rev. Neurosci. 19, 383-384. doi: 10.1038/s41583-018-0012-5

Richardson-Jones, J. W., Craige, C. P., Nguyen, T. H., Kung, H. F., Gardier, A. M., and Dranovsky, A. (2011). Serotonin-1A autoreceptors are necessary and sufficient for the normal formation of circuits underlying innate anxiety. J. Neurosci. 31, 6008-6018. doi: 10.1523/JNEUROSCI.5836-10.2011

Savitz, J., Lucki, I., and Drevets, W. C. (2009). 5-HT(1A) receptor function in major depressive disorder. Prog. Neurobiol. 88, 17-31. doi: 10.1016/j. pneurobio.2009.01.009

Scheinost, D., Sinha, R., Cross, S. N., Kwon, S. H., Sze, G., Constable, R. T., et al. (2017). Does prenatal stress alter the developing connectome? Pediatr. Res. 81, 214-226. doi: 10.1038/pr.2016.197

Schwarz, J. M., Sholar, P. W., and Bilbo, S. D. (2012). Sex differences in microglial colonization of the developing rat brain. J. Neurochem 120, 948-963. doi: 10.1111/j.1471-4159.2011.07630.x

Shagura, M., Li, X., Al-Khrasani, M., Shakibaei, M., Tafelski, S., Fürst, S., et al. (2016). Membrane-bound glucocorticoid receptors on distinct nociceptive neurons as potential targets for pain control through rapid non-genomic effects. Neuropharmacology 111, 1-13. doi: 10.1016/j.neuropharm.2016.08.019

Sharifi, H., Nayebi, A. M., Farajnia, S., and Haddadi, R. (2015). Effect of chronic administration of buspirone and fluoxetine on inflammatory cytokines in 6hydroxydopamine-lesioned rats. Drug Res. 8, 393-397. doi: 10.1055/s-00341374615

Shields, S. D., Cavanaugh, D. J., Lee, H., Anderson, D. J., and Basbaum, A. I. (2010). Pain behavior in the formalin test persists after ablation of the great majority of C-fiber nociceptors. Pain 151, 422-429. doi: 10.1016/j.pain.2010.08.001

Soares-Cunha, C., Coimbra, B., Borges, S., Domingues, A. V., Silva, D., Sousa, N., et al. (2018). Mild prenatal stress causes emotional and brain structural modifications in rats of both sexes. Front. Behav. Neurosci. 12:129. doi: 10.3389/fnbeh.2018.00129

Sternberg, W. F., and Ridgway, C. G. (2003). Effects of gestational stress and neonatal handling on pain, analgesia, and stress behavior of adult mice. Physiol. Behav. 78, 375-383. doi: 10.1016/s0031-9384(03)00015-5

Stuivenga, M., Giltay, E. J., Cools, O., Roosens, L., Neels, H., and Sabbe, B. (2019). Evaluation of vilazodone for the treatment of depressive and anxiety disorders. Expert. Opin. Pharmacother. 20, 251-260. doi: 10.1080/14656566.2018.1549542

Sun, L., Gooding, H. L., Brunton, P. J., Russell, J. A., Mitchell, R., and Fleetwood-Walker, S. (2013). Phospholipase D-mediated hypersensitivity at central synapses is associated with abnormal behaviours and pain sensitivity in rats exposed to prenatal stress. Int. J. Biochem. Cell Biol. 45, 2706-2712. doi: 10.1016/j.biocel.2013.07.017

Taylor, B. K., Akana, S. F., Peterson, M. A., Dallman, M. F., and Basbaum, A. I. (1998). Pituitary-adrenocortical responses to persistent noxious stimuli in the awake rat: endogenous corticosterone does not reduce nociception in the formalin test. Endocrinology 139, 2407-2413. doi: 10.1210/en.139.5.2407

Turcotte-Cardin, V., Vahid-Ansari, F., Luckhart, C., Daigle, M., Geddes, S. D., Tanaka, K., et al. (2019). Loss of adult 5-HT1A autoreceptors results in a paradoxical anxiogenic response to antidepressant treatment. J. Neurosci. 39, 1334-1346. doi: 10.1523/JNEUROSCI.0352-18.2018

Urien, L., Gaillard, S., Lo Re, L., Malapert, P., Bohic, M., Reynders, A., et al. (2017). Genetic ablation of GINIP-expressing primary sensory neurons strongly impairs formalin-evoked pain. Sci. Rep. 7:43493. doi: 10.1038/srep43493
Valera, E., Ubhi, K., Mante, M., Rockenstein, E., and Masliah, E. (2014). Antidepressants reduce neuroinflammatory responses and astroglial $\alpha$-synuclein accumulation in a transgenic mouse model of multiple system atrophy. Glia 62, 317-337. doi: 10.1002/glia.22610

van den Bergh, B. R. H., Dahnke, R., and Mennes, M. (2018). Prenatal stress and the developing brain: risks for neurodevelopmental disorders. Dev. Psychopathol. 30, 743-762. doi: 10.1017/s0954579418000342

Van den Hove, D. L., Lauder, J. M., Scheepens, A., Prickaerts, J., Blanco, C. E., and Steinbusch, H. W. (2006). Prenatal stress in the rat alters 5-HT1A receptor binding in the ventral hippocampus. Brain Res. 1090, 29-34. doi: 10.1016/j. brainres.2006.03.057

VanRyzin, J. W., Pickett, L. A., and McCarthy, M. M. (2018). Microglia: driving critical periods and sexual differentiation of the brain. Dev. Neurobiol. 78, 580-592. doi: 10.1002/dneu.22569

Vartazarmian, R., Malik, S., Baker, G. B., and Boksa, P. (2005). Longterm effects of fluoxetine or vehicle administration during pregnancy on behavioral outcomes in guinea pig offspring. Psychopharmacology 178, 328-338. doi: 10.1007/s00213-004-2003-7

Waddell, B. J., and Atkinson, H. C. (1994). Production rate, metabolic clearance rate and uterine extraction of corticosterone during rat pregnancy. J. Endocrinol. 143, 183-190. doi: 10.1677/joe.0.1430183

Wang, S. M., Han, C., Lee, S. J., Patkar, A. A., Masand, P. S., and Pae, C. U. (2015). Vilazodone for the treatment of major depressive disorder: focusing on its clinical studies and mechanism of action. Psychiatry. Investig 12, 155-163. doi: $10.4306 /$ pi.2015.12.2.155

Wang, Q. P., and Nakai, Y. (1994). The dorsal raphe: an important nucleus in pain modulation. Brain Res. Bull. 34, 575-585. doi: 10.1016/0361-9230(94) 90143-0

Weinstock, M. (1997). Does prenatal stress impair coping and regulation of hypothalamic-pituitary-adrenal axis? Neurosci. Biobehav. Rev. 21, 1-10. doi: 10.1016/s0149-7634(96)00014-0

Weinstock, M. (2008). The long-term behavioural consequences of prenatal stress. Neurosci. Biobehav. Rev. 32, 1073-1086. doi: 10.1016/j.neubiorev.2008.03.002

Weinstock, M. (2010). Intrauterine factors as determinants of depressive disorder. Isr. J. Psychiatry Relat. Sci. 47, 36-45.

Weinstock, M. (2017). Prenatal stressors in rodents: effects on behavior. Neurobiol. Stress 6, 3-13. doi: 10.1016/j.ynstr.2016.08.004

Wilson, T. K., and Tripp, J. (2018). Buspirone. StatPearls [Internet]. Treasure Island, FL: StatPearls Publishing.

Wyrwoll, C. S., and Holmes, M. C. (2012). Prenatal excess glucocorticoid exposure and adult affective disorders: a role for serotonergic and catecholamine pathways. Neuroendocrinology 95, 47-55. doi: 10.1159/000331345

Zammataro, M., Merlo, S., Barresi, M., Parenti, C., Hu, H., Sortino, M. A., et al. (2017). Chronic treatment with fluoxetine induces sex-dependent analgesic effects and modulates HDAC2 and mGlu2 expression in female mice. Front. Pharmacol. 8:743. doi: 10.3389/fphar.2017.00743

Zhang, L., Yin, J. B., Hu, W., Zhao, W. J., Fan, Q. R., Qiu, Z. C., et al. (2018). Analgesic effects of duloxetine on formalin-induced hyperalgesia and its underlying mechanisms in the CeA. Front. Pharmacol. 9:317. doi: 10.3389/fphar.2018.00317

Zouikr, I., Bartholomeusz, M. D., and Hodgson, D. M. (2016). Early life programming of pain: focus on neuroimmune to endocrine communication. J. Transl. Med. 14:123. doi: 10.1186/s12967-016-0879-8

Conflict of Interest Statement: The authors declare that the research was conducted in the absence of any commercial or financial relationships that could be construed as a potential conflict of interest.

Copyright (c) 2019 Butkevich, Mikhailenko, Vershinina and Barr. This is an open-access article distributed under the terms of the Creative Commons Attribution License (CC BY). The use, distribution or reproduction in other forums is permitted, provided the original author(s) and the copyright owner(s) are credited and that the original publication in this journal is cited, in accordance with accepted academic practice. No use, distribution or reproduction is permitted which does not comply with these terms. 